\title{
Optic nerve crush activates the genomic fabrics of the Complement cascade and Delta-Notch signaling
}

\author{
Pedro Henrique Victorino ${ }^{1}$, Camila Marra ${ }^{2}$, Dumitru Andrei Iacobas ${ }^{3,4}$, Sanda Iacobas ${ }^{5}$, David C. \\ Spray ${ }^{4}$, Rafael Linden ${ }^{6}$, Daniel Adesse ${ }^{7, *}$ and Hilda Petrs-Silva ${ }^{8, *}$ \\ 1 Laboratório de Neurogênese, Instituto de Biofísica Carlos Chagas Filho, UFRJ; phvictorino.phv@gmail.com \\ 2 Laboratório de Neurogênese, Instituto de Biofísica Carlos Chagas Filho, UFRJ; milamarra@hotmail.com \\ 3 Personalized Genomics Laboratory, Center for Computational Systems Biology, Prairie View A\&M \\ University, Prairie View, TX, USA; Domminick P. Purpura Department of Neuroscience, Albert Einstein \\ College of Medicine, Yeshiva University; daiacobas@pvamu.edu \\ 4 Dominick P. Purpura Department of Neuroscience, Albert Einstein College of Medicine, Yeshiva \\ University; david.spray@einstein.yu.edu \\ 5 Department of Pathology, New York Medical College; sanda.iacobas@einstein.yu.edu \\ 6 Laboratório de Neurogênese, Instituto de Biofísica Carlos Chagas Filho, UFRJ; : rlinden@biof.ufri.br \\ 7 Laboratório de Biologia Estrutural, Instituto Oswaldo Cruz, Fiocruz; adesse@ioc.fiocruz.br \\ 8 Laboratório de Neurogênese, Instituto de Biofísica Carlos Chagas Filho, UFRJ; hilda@biof.ufrj.br \\ * D.A. and H.P.S. contributed equally as co-senior authors \\ * Correspondence: adesse@ioc.fiocruz.br; +5521987968788 (D.A.); hilda@biof.ufrj.br; +5521995030404 (H.P.S.)
}

\begin{abstract}
Glaucoma is a multifactorial neurodegenerative disease, characterized by degeneration of the retinal ganglion cells (RGCs). There has been little progress in developing efficient strategies for neuroprotection in glaucoma. We profiled the retina transcriptome of Lister Hooded rats at 2 weeks after optic nerve crush (ONC) and applied systems biology approaches to better understand the molecular mechanisms related with the retinal remodeling after induction of RGC degeneration. We observed a higher Relative Expression Variability after ONC. Gene expression stability was used as a measure of transcription control and disclosed a robust reduction in the number of very stably expressed genes. Enrichment analysis showed that Complement cascade and Notch signaling pathway were the main affected pathways after ONC. To expand our studies of these two pathways, we examined the coordination of gene expressions within each pathway and with the entire transcriptome. ONC increased the number of synergistically coordinated pairs of genes and the number of similar profiles. This study provided novel findings beyond the regulation of individual gene expression and disclosed changes in the control of expression by Complement cascade and Notch signaling functional pathways important for both RGC degeneration and remodeling of the retinal tissue after ONC.
\end{abstract}

Keywords: glaucoma, retina ganglion cell degeneration, microarray, genes coordination, notch signaling pathway, complement cascade.

\section{Introduction}

Glaucoma is a multifactorial disease characterized by degeneration of the neurons known as retinal ganglion cells (RGC), and their long axons which transmit visual information from the retina to the brain [1]. A variety of in vivo animal models have been used to unravel the mechanisms of both RGC degeneration and reorganization of the retina. The animals were subjected to either acute or chronic elevation of intraocular pressure, transection or crush of the optic nerve, as well as the spontaneous glaucoma-like disease (on mice of the DBA/2J strain) [2-4]. However, there has been little progress in developing efficient strategies for neuroprotection in glaucoma.

The retina is a complex, multilayered tissue of the central nervous system (CNS) composed of diverse neurons, glia, and vascular cells, as well as a rich extracellular matrix. Recent studies of single-cell RNA-sequencing disclosed cell type-specific molecular markers [5]. Laser capture 
microdissection was also used to isolate individual cells from the retinal tissue and compare genes expressed in RGCs of either normal or glaucomatous retinas [6]. However, similar to other neurodegenerative conditions [7], mechanisms involved in glaucomatous neurodegeneration appear to depend on a complex interplay of signaling pathways and often involve multicellular networks [8-10]. The systemic character of such events suggests that an examination of the whole tissue transcriptional landscape may help guide both further investigations into the pathophysiology, as well as the development of novel therapeutic approaches to glaucoma.

Transcriptional changes following either acute or chronic optic nerve injury have been identified in animal models ranging from zebrafish to non-human primates [11-13]. It is usually assumed that insights into functional changes caused by RGC injury in rodents may help elucidate the course of glaucomatous neurodegeneration in humans. Microarray-based transcriptome analyses are currently available for rodent models of glaucoma [14-16], retinal and optic disc injury [17-18] and ischemic damage [19].

Overall, the data suggest evolving stages associated with altered gene expression, roughly defined as follows: an acute phase, within hours, with transient up-regulation of both immediate-early response genes and inflammatory responses [20-22]; a sub-acute phase, between 1 and 3 days, characterized by the expression of cell-cycle and cell death genes [23]; and a late chronic phase, at 5 to 7 days, characterized by the expression of genes involved in structural remodeling of neurons and glia [24-29]. In the earliest stage, genes related with triggering of apoptosis have been found upregulated in response to retinal injury [30-32]. In the subacute phase, in line with apoptotic RGC death following optic nerve damage, studies identified upregulation of genes related with the execution phase of apoptosis, as well as downregulation of cytoprotective and anti-apoptotic genes [33]. The up-regulated pro-apoptotic genes include caspase 3, tumor necrosis factor receptor type 1 associated death domain (TRADD), tumor necrosis factor receptor superfamily member 1a (TNFR1a) and BCL2 associated X apoptosis regulator (Bax). Downregulated cytoprotective and anti-apoptotic genes include $\mathrm{X}$-linked inhibitor of apoptosis (XIAP), mitogen activated protein kinase 1 (Mapk1), Ras/Rac guanine nucleotide exchange factor 1 (Sos1), c-Raf-1, and YY1 [34]. In later stages, only elevated intraocular pressure and optic nerve transection models were explored by microarray analysis, and retinal changes were associated with altered expression of genes with roles in regeneration, synaptic plasticity, axonogenesis, neuronal projections, and neuron differentiation [35-40].

In the present study, we used Agilent gene expression microarrays and computational approaches to identify the differentially expressed genes in the rat retina at 14 days after optic nerve crush (ONC) compared to control (CTR) sham operated animals. ONC is a well-established model that mimics glaucomatous optic nerve injury [41]. At that relatively late stage after the lesion, a small number of RGCs remain in the retina, thus the modified transcriptome is likely to reflect mainly the adaptation of the tissue to the loss of those [42].

Enrichment analysis performed in accordance to previous studies [43-44] shows Complement cascade and Notch signaling pathway components as major players in the retina 14 days after ONC. We went beyond the enrichment analysis to extract more information of the transcriptome such as the relative expression variability and the derived gene expression stability. Moreover, we have analyzed the coordination of gene expressions within each enriched pathway and with the entire transcriptome to determine the ONC-induced remodeling of the associated genomic fabrics. The genomic fabric of a given pathway was defined as the transcriptome associated to the most interconnected and stably expressed gene network responsible for that pathway [45]. These less traditional analyses provide additional insight into the responsible mechanisms for both RGC death and adaptation of the retinal tissue following ONC. 


\section{Materials and Methods}

\subsection{Animal handling}

27 eight weeks old female Lister Hooded rats were housed in plastic cages, on a 12-hour light-dark cycle, with water and food ad libitum. All experiments were carried out in accord with the ARVO Statement for the Use of Animals in Ophthalmic and Vision Research, and the protocol approved by the Institutional Animal Experimentation Ethics Committee (\#01200.001568/2013-87).

\subsection{Quantification of retinal ganglion cell survival}

Cell survival was quantified using the lipophilic tracer DiI (1,1'-dioctadecyl-3,3,3,3'-tetramethylindocarbocyanine perchlorate, Invitrogen) for retrograde labeling. DiI was bilaterally injected into the superior colliculi of one-week old neonate rats. This technique allowed us to label virtually all the RGCs [46]. Seven weeks after DiI injection, rats underwent an optic nerve crush (ONC). Two weeks after ONC, animals were euthanized. At this time point, the cells that remained alive were detectable by DiI labeling and quantified. For that purpose, retinas were dissected after fixation with $4 \%$ paraformaldehyde for $15 \mathrm{~min}$ at room temperature, washed three times with Phosphate-Buffered Saline (PBS, Sigma), and counterstained with Sytox Green (ThermoFisher) to visualize cell nuclei. Whole retinas were analyzed by confocal microscopy; Cell counts were done in a double-blind manner and were averaged across evenly distributed of each retina. Statistical analysis was through an unpaired two-tailed t-test using the software GraphPad Prism 5.02 (1992-2004 GraphPad Software, Inc.).

\subsection{Optic nerve crush}

The rats were divided into two experimental groups: optic nerve crush $(\mathrm{n}=16$, hereafter denoted by ONC) and control, sham operated, ( $\mathrm{n}=11$, denoted by CTR). Rats were deeply anesthetized by intraperitoneal injection of a mixture of xylazine $(10 \mathrm{mg} / \mathrm{kg}$ body weight) and ketamine $(60 \mathrm{mg} / \mathrm{kg}$ body weight). Under a stereoscopic microscope, the right optic nerve was accessed through an incision made in the superior orbital rim, and the conjunctiva was dissected with forceps towards the back of the eye to expose the retrobulbar portion of the optic nerve. The lesion was done by crushing the optic nerve for $10 \mathrm{~s}$ at $3 \mathrm{~mm}$ from the optic disc, using a pair of watchmaker's forceps. Sham operated rats underwent the same procedure, except that the forceps were not closed. Animals were euthanized two weeks after the procedure.

\subsection{Microarray gene expression}

We applied an optimized protocol [47] for RNA extraction (Qiagen RNeasy mini-kit), reverse transcription (adding fluorescent tags) and hybridization onto Agilent G2519F 60mer two-colour gene expression rat $4 \times 44 \mathrm{k}$ arrays in the "multiple yellow" design that provides maximum flexibility in comparing the conditions and $100 \%$ usage of the resources [48]. RNA concentrations before and after reverse transcription were estimated with a NanoDrop ND2000 Spectrophotometer, and purity was assessed with Agilent RNA 6000 Nano kit in an Agilent 2100 Bioanalyzer. RIN (RNA Integrity Number) of at least 8.0 was considered as satisfactory. For each experimental group (CTR or ONC), four separated retinas were profiled individually. RINs of the selected OPC samples were: 8.20, 8.40, 9.10, 8.50, while those for the CTR samples were: 8.40, 8.20, 8.50, 8.60. With each array, samples of $825 \mathrm{ng}$ of Cy3 labeled RNA from the retina of a rat subjected to ONC and $825 \mathrm{ng}$ Cy5-labeled RNA from the retina of a CTR rat were co-hybridized for $17 \mathrm{~h}$ at $65^{\circ} \mathrm{C}$. Chips were scanned with an Agilent G2539A dual laser scanner at $5 \mu \mathrm{m}$ pixel size/20-bit, and raw data were collected with Agilent Feature Extraction software v. 11.1.1. 


\subsection{Data processing}

We disregarded all spots showing signs of local corruption or with foreground fluorescence less than twice their background in any one of the 8 profiled samples. Data were normalized by an in-house developed, iterative method that alternates intra- and inter-array normalization to the median of the background-subtracted fluorescence of the valid spots, until the overall maximum error of estimate reaches less than 5\% [49]. Normalized expression levels were organized into redundancy groups composed of all spots probing the same gene and represented by the weighted average of the values of individual spots.

The Relative Expression Variability (REV = median of the Bonferroni like-corrected chi-square interval estimate of the pooled coefficient of variation) was taken as a statistical estimate of the expression variability of one gene among biological replicas [50].

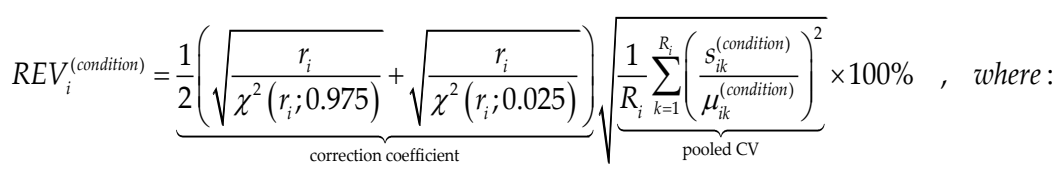

condition $=O P C, C T R$

$\mu_{i k}=$ average expression level of gene $i$ probed by spot $k\left(=1, \ldots, R_{i}\right)$ in the 4 biological replicas

$s_{i k}=$ standard deviation of the expression level of gene $i$ probed by spot $k$

$r_{i}=4 R_{i}-1=$ number of degrees of freedom

$R_{i}=$ number of microarray spots probing redundantly gene $i$

The genes were then ordered according to decreasing variability, such that the first percentile (or gene expression stability score, GES $<1$ ) contained the most unstably expressed and the 100th percentile (GES > 99) the most stably expressed genes [51].

A gene was scored as significantly regulated in ONC with respect to CTR if the absolute fold-change $|x|$ exceeded the cut-off (CUT) computed for that gene (Eq. 1), AND the p-value of the heteroscedastic $t$-test for the equal expressions was $<0.05$. Thus, we replaced an arbitrary uniform absolute fold-change cut-off (e.g. 1.5x) for all genes with a value that accounts for the combined contributions of the technical noise and biological expression variability of each gene independently [52]. This composite criterion, in which the cut-offs were computed with Bonferroni-type corrections applied to the redundancy groups [53-54], eliminates most of the false positives without increasing the number of false negatives (Eq. 2).

$$
\begin{aligned}
& \left|x_{i}^{(\mathrm{CTR} \rightarrow O P C)}\right|>\left|C U T_{i}^{(\mathrm{CTR} \rightarrow O P C)}\right|=1+\frac{1}{100} \sqrt{2\left(\left(R E V_{i}^{(\mathrm{CTR})}\right)^{2}+\left(R E V_{i}^{(\mathrm{OPC})}\right)^{2}\right)}, \text { where }: \\
& x_{i}^{(\mathrm{CTR} \rightarrow \mathrm{OPC})}=\left\{\begin{array}{c}
\frac{\mu_{i}^{(\mathrm{OPC})}}{\mu_{i}^{(\mathrm{CTR})}}, \text { if } \mu_{i}^{(\mathrm{OPC})} \geq \mu_{i}^{(\mathrm{CTR})} \\
-\frac{\mu_{i}^{(\mathrm{CTR})}}{\mu_{i}^{(\mathrm{OPC})}}, \text { if } \mu_{i}^{(\mathrm{OPC})}<\mu_{i}^{(\mathrm{CTR})}
\end{array} \mid \mu_{i}^{(\mathrm{OPC} / \mathrm{CTR})}=\frac{1}{R_{i} \sum_{k=1}^{R_{i}} \mu_{i k}^{(\mathrm{OPC} / \mathrm{CTR})}}\right. \\
& |a|=\text { absolute value of } a
\end{aligned}
$$

\subsection{Analysis of predicted protein-protein interactions}

Interactions among proteins encoded by differentially expressed genes were assessed using STRING (https://string-db.org/, [55]), which provides uniquely comprehensive coverage and ease of access to information of both experimental and predicted interaction. A protein-protein interaction 
network was constructed, in which the interactions of ONC vs. CTR differentially expressed genes (DEGs) were mapped to STRING, based on information including the sequence characters and structures. Each protein-protein interaction stored in the STRING database receives a confidence score between zero and one. These scores indicate the estimated probability that an interaction is biologically significant, specific and reproducible. To highlight the most biologically relevant interactions, we used a confidence score cutoff of 0.4 .

\subsection{Analyses of enrichment}

Pathvisio3 (www.pathvisio.org, [56]) was used to identify pathways significantly altered, and the Gene Ontology Knowledgebase (www.geneontology.org) was used to identify main Biological Processes, Molecular Functions and Cellular Components affected by Optic Nerve Crush. The pathways were ranked based on a standardized difference indicator ( $Z$ score). Pathways with $Z$ score $>2$ and $p$ value $<0.05$ were accepted as significantly altered. Graphical representation of the molecular pathways was based on the Kyoto Encyclopedia for Genes and Genomes (KEGG, www.genome.jp/kegg/, Kanehisa Laboratories, Japan; [57]).

The EnrichR platform (http://amp.pharm.mssm.edu/Enrichr/, [58]) contains a collection of diverse gene set libraries available for analysis, and was used to disclose disease-related perturbations by differentially expressed genes, according to the GEO (Gene Expression Omnibus) database.

\subsection{Coordination of expression}

We used the variation in gene expression among multiple biological replicas to calculate the pair-wise Pearson correlation coefficients $\rho$ between the levels of expression of gene pairs. Two genes were scored as: synergistically expressed if their expression levels had a positive covariance within biological replicas antagonistically expressed when they manifested opposite tendencies (i.e., negative covariance) or independently expressed, when their transcription levels were not correlated (close to zero covariance). In the case of four biological replicas, the $(p<0.05)$ significant synergistically expressed genes have $\rho>0.90$, antagonistically expressed genes have $\rho<-0.90$; and independently expressed ones have $|\rho|<0.05$. The set of correlation coefficients between the expression level of a particular gene and of each other gene within the biological replicas forms the coordination profile of that gene. The profiles of two genes can be similar, opposite or neutral. Two genes were considered as having similar coordination profiles when there is significant overlap of their synergistically, antagonistically and independently expressed partners; genes were considered as having opposite coordination profiles when most of the synergistically expressed partners of one gene were antagonistically expressed partners for the other, and most of the independently expressed partners of one gene were synergistically or antagonistically expressed for the other [53-54].

\subsection{Quantitative Real-Time PCR}

To validate selected genes, a new set of animals ( $n=4$ per group) was used for qRT-PCR. Total RNA $(2 \mu \mathrm{g})$ isolated from retinas using TRIzol reagent (Invitrogen, Carlsbad, CA, USA), was reversely transcribed into cDNA with the SuperScript ${ }^{\mathrm{TM}}$ III Reverse Transcriptase (Invitrogen, Carlsbad, CA, USA). RT-PCR was done with SYBR Green Mix (Promega, Madison, WI, USA) in a 7500 Real-Time PCR system (Applied Biosystems, Waltham, MA, UK), to detect the expression of Cd74 (Cd74 molecule, major histocompatibility complex, class II invariant chain) and C3 (Complement component 3). Results were normalized to the expression of 2 housekeeping genes: rat glyceraldehyde-3-phosphate dehydrogenase (GAPDH) and Mitogen-Activated Protein Kinase 1 (MAPK1). Primers were: Cd74 Forward 5'- GAACCTGCAACTGGAGAACC-3'; Reverse 5'CTTCGTAAGCAGGTGCATCA-3'; C3 Forward 5'- GCATCAGTCACAGGATCAGGTCA-3'; Reverse 5'- ATCAAAATCATCCGACAGCTCTATC-3'; GAPDH Forward 5'- 
GACATGCCGCCTGGAGAAAC-3'; Reverse 5'- AGCCCAGGATGCCCTTTAGT-3'; MAPK1 Forward 5'-TGTTGCAGATCCAGACCATG-3'; Reverse 5'-CAGCCCACAGACCAAATATCA-3'.

The PCR program was: denaturation at $95^{\circ} \mathrm{C}$ for $5 \mathrm{~s}$, annealing at $60^{\circ} \mathrm{C}$ for $30 \mathrm{~s}$, elongation at $68^{\circ} \mathrm{C}$ for $20 \mathrm{~s}$ for 40 cycles. Each sample was applied in technical duplicates, and fold changes were calculated using the 2- $\Delta \Delta \mathrm{CT}$ method of relative quantification. For each gene tested, all experimental and control retinas were assessed in the same experiment. The data were normalized to the geometric mean of the two housekeeper genes and expressed as fold change. Statistical analysis was done using GraphPad Prism Software (Mean \pm SEM) using unpaired two-tailed Student's t-test. Differences were accepted as significant when $\mathrm{p}<0.05$.

\section{Results}

\subsection{Histopathological observations}

As expected, ONC induced robust loss of retinal ganglion cells (RGCs). At 14 days after the procedure, control retinas displayed an average of $1.780 \pm 134$ cells $/ \mathrm{mm}^{2}$, retrogradely labeled with DiI, whereas ONC retinas showed a reduction of approximately $60 \%$ of RGCs, to $768 \pm 65$ cells $/ \mathrm{mm}^{2}$ (Figure 1a-c).
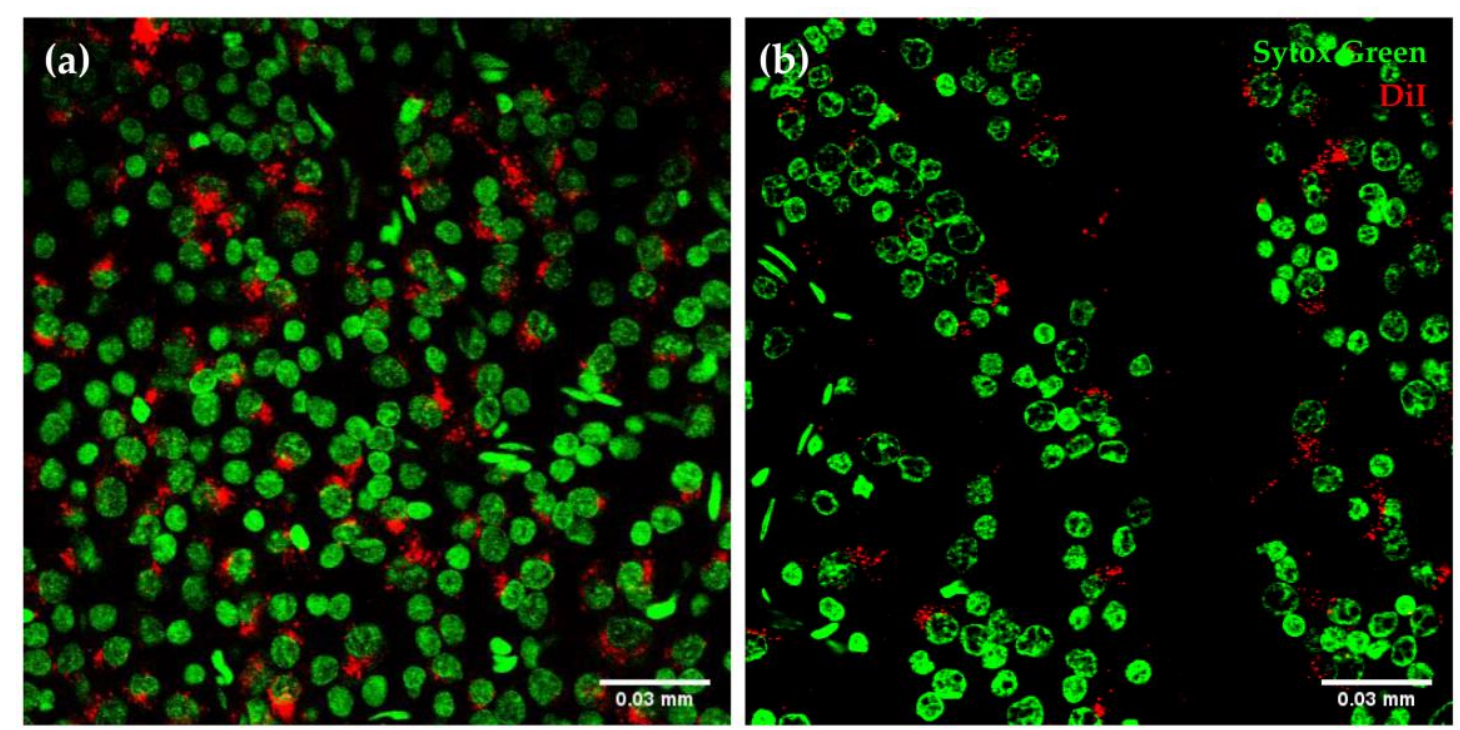

(c)

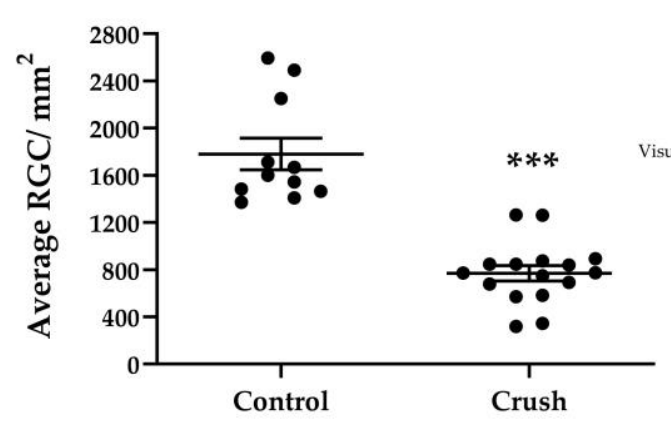

(d)

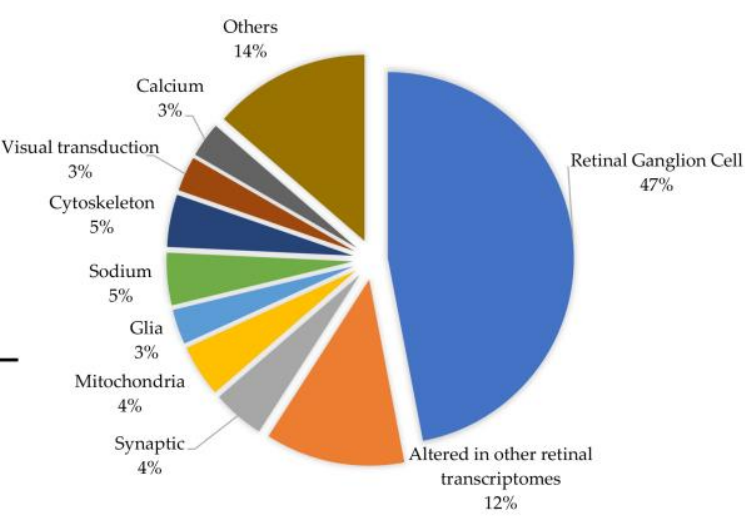

Figure 1. General profile of the number retinal ganglion cell (RGC) after the ONC. (a) Retina from control eye showing the pattern of RGCs retrograde labeling by DiI (red). Nucleus of remaining cells are shown by SYTOX Green staining in green (b) After ONC retinas showed decreased numbers of RGC at 14 days after ONC. (c) Retina quantification showing a reduction of approximately $60 \%$ of DiI-retrogradely labelled RGCs. Control retinas displayed an average of $1.780 \pm 134 \mathrm{cells} / \mathrm{mm}^{2}$ and ONC retinas presented 768 \pm 65 cells $/ \mathrm{mm}^{2}$. [Difference between means (ONC $\left.\mathrm{n}=16-\mathrm{CTR} \mathrm{n}=11\right)-1012$ 
$\pm 60.98 \rho<0.0001]$. (d) Pie chart of the distribution of down-regulated genes based on GeneCard and Pubmed analysis showed that the majority (47\%) are expressed in RGC and 12\% were described to be decreased in other retinal microarray studies of RGC degeneration.

\subsection{Transcriptomic alterations in rat retina after optic nerve crush}

The experimental details, as well as both raw and normalized expression data from the microarrays were deposited and are publicly available at Gene Expression Omnibus (GEO accession number GSE133563). Among 17,657 unigenes quantified in our microarrays, expression of $1707(9.7 \% \%)$ was significantly altered in ONC samples with respect to CTR, of which 1167 (6.6\%) were up- and 540 (3.1\%) were down-regulated. Table S1 in the Appendix presents the most down-regulated 50 genes and Table S2 the most up-regulated 50 genes. Quantitative RT-PCR validated two of the highest up-regulated genes (Cd74 and C3), and their respective fold-change increase in expression, compared with control retinas, were consistent with the results of the arrays (Table S3).

Many of the down-regulated genes found in our arrays have been previously described as markers of RGCs [5-6] (Figure 1(d) and Table S7). Notably, RGC markers had the highest downregulation fold changes, as for example, peripherin $(-12.7 x)$, neurofilament heavy, medium and light polypeptides $(-11.4 x,-11.8 x$ and $-6.8 x$, respectively), gamma synuclein $(-10.8 x)$, POU class 4 homeobox 2 (or Brn3A, -7.3x), Thy-1 cell surface antigen $(-3.9 x)$, synaptotagmin II $(-2.4 x)$, tubulin, beta 3 class III $(-1.9 x)$, internexin neuronal intermediate filament protein $(-1.9 x)$, alpha-internexin $(-1.9 x)$ and pannexin $2(-1.89 x)$. In addition, the retinal ganglion cell neurotrophic factor neuritin 1 [59] was also strongly down-regulated after ONC, with a $-18.8 x$ decrease when compared to controls (Figure 2B). The EnrichR software, a tool to determine disease-enriched perturbations in the transcriptome that uses the GEO database, showed that among the down-regulated genes at 14 days after ONC, the top disease signature was "Glaucoma associated with systemic syndromes" (Table S4).

\subsection{Protein-protein interaction encoded by the most down-regulated genes}

We used the STRING platform to predict protein-protein interaction (PPI) networks. Among the down-regulated genes, only 22 showed a network of 21 interactions, with a medium confidence score of 0.4. Enrichment analysis using the Gene Ontology database indicated that the main Biological Processes altered by ONC were Intermediate Filament Cytoskeleton Organization, Intermediate Filament bundle Assembly and Response to Acrylamide, all of which include neurofilaments (Figure2(a)), a major component of the optic nerve axons. Among Molecular Functions, ONC affected networks of Protein Binding, Binding and Protein Heterodimerization Activity (Figure 2(b)). Finally, among cellular components, ONC affected Cell Projection, Axon and Neuron Projection (Figure 2(c)). All such functional interactions are consistent with retrograde degeneration as a consequence of ONC. 
(a)
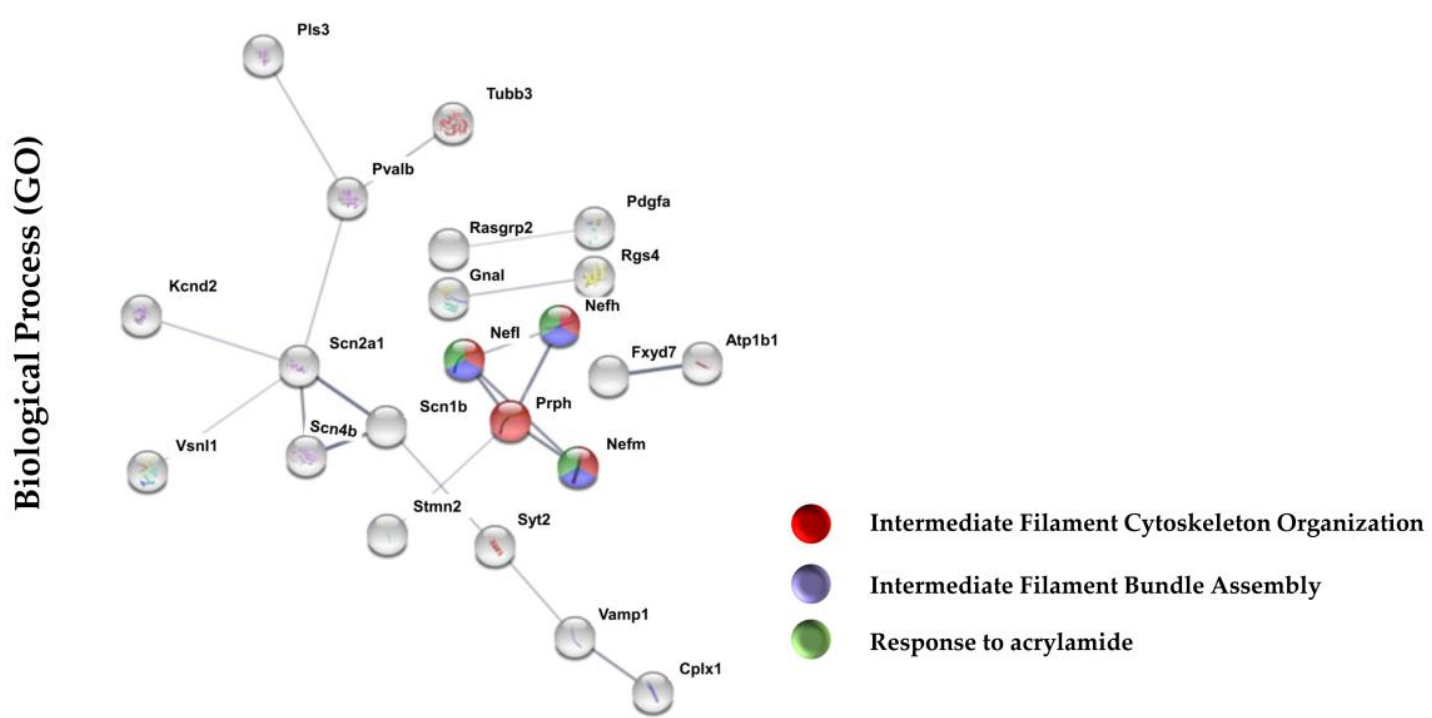

(b)
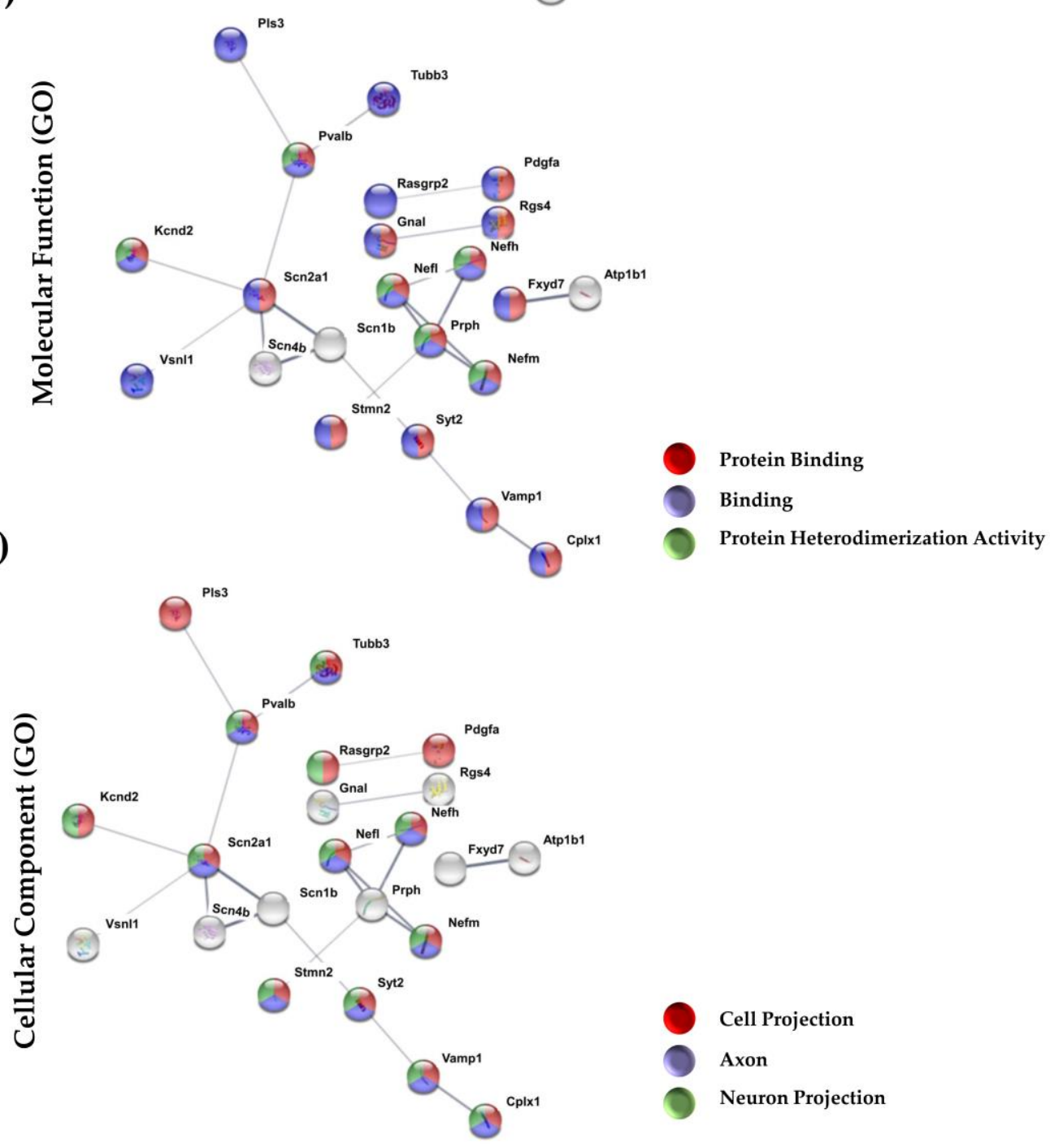

Figure 2: Protein-protein interaction (PPI) network composed with down-regulated genes after the ONC. Among 66 down-regulated genes, 21 interactions between 22 genes were found using STRING software, with a confidence cutoff of 0.4. Nodes labeled with the encoding gene symbol indicate proteins and the lines represent the corresponding interactions. The confidence score of each interaction is mapped to the line thickness (the thicker the line, the more evidence to support the interaction). The network was then enriched according to Gene Ontology database. The 
categories of Gene Ontology are depicted: (a) Biological Processes; (b) Molecular Function and (c) Cellular Components and the 3 most significantly enriched categories were used to color the nodes of the interaction networks.

\subsection{Protein-protein interaction encoded by the most up-regulated genes}

Consistent with previous studies [15-18; 29], the group of 50 most up-regulated genes (Table S2) include inflammatory response-related genes, such as Cd74 molecule, major complex, class II invariant chain (25.6x), H-2 class II histocompatibility antigen gamma chain (MHC class II-associated invariant chain) (Ia antigen-associated invariant chain) (Ii) (CD74 antigen) (11.6x), follistatin-like 3 (5.3x), serpin peptidase inhibitor, clade $G$, member 1 (3.5x) and Eph receptor A2 (3.3x). Similar to the down-regulated set of genes, the EnrichR platform indicated glaucomatous/neurodegenerative transcriptomic profile as the main systemic syndrome or disease (Table S5). Further, PPI analysis showed that out of the up-regulated genes, 64 had at least one interaction, that form a network of 129 interactions with a medium confidence score of 0.4 (Figure 3). Followed by enrichment analysis, the main Biological Processes identified were: Immune System, Regulation of Cell Proliferation and Innate Immune Response (Figure 43(a)). Among Molecular Functions, Binding, Protein Binding and Ion Binding categories presented the most pronounced interactions, with 33, 25 and 24 altered genes, respectively (Figure 3(b)). As for Cellular Components, interactions were found in Extracellular Space, Extracellular Region and Extracellular Region Part categories (Figure 3(c)). Both Molecular Function and Cellular Components are consistent with immune system signaling, the main Biological Process identified among the up-regulated genes. 

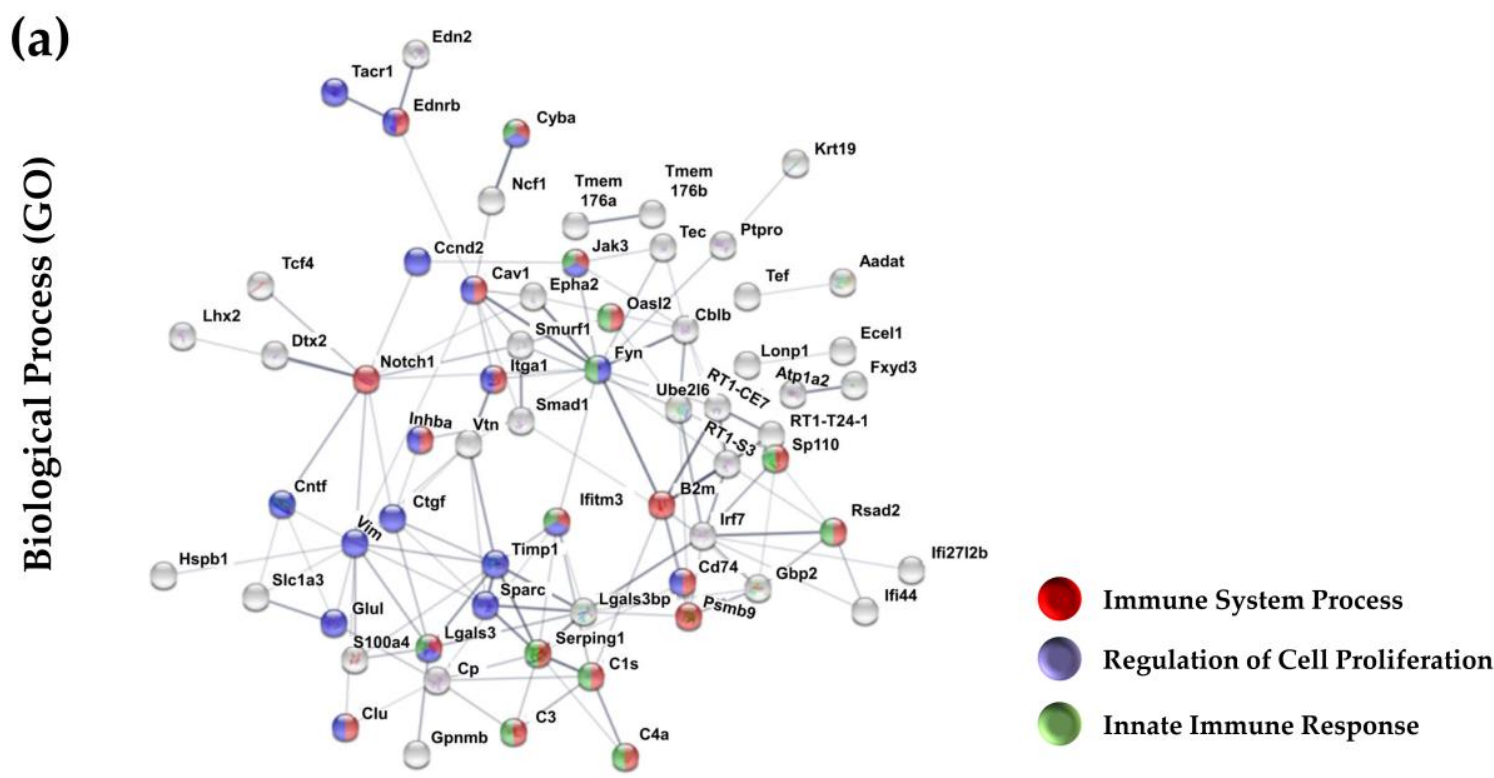

(b) $e_{\text {Ednrt }}^{\text {Tacr }}$
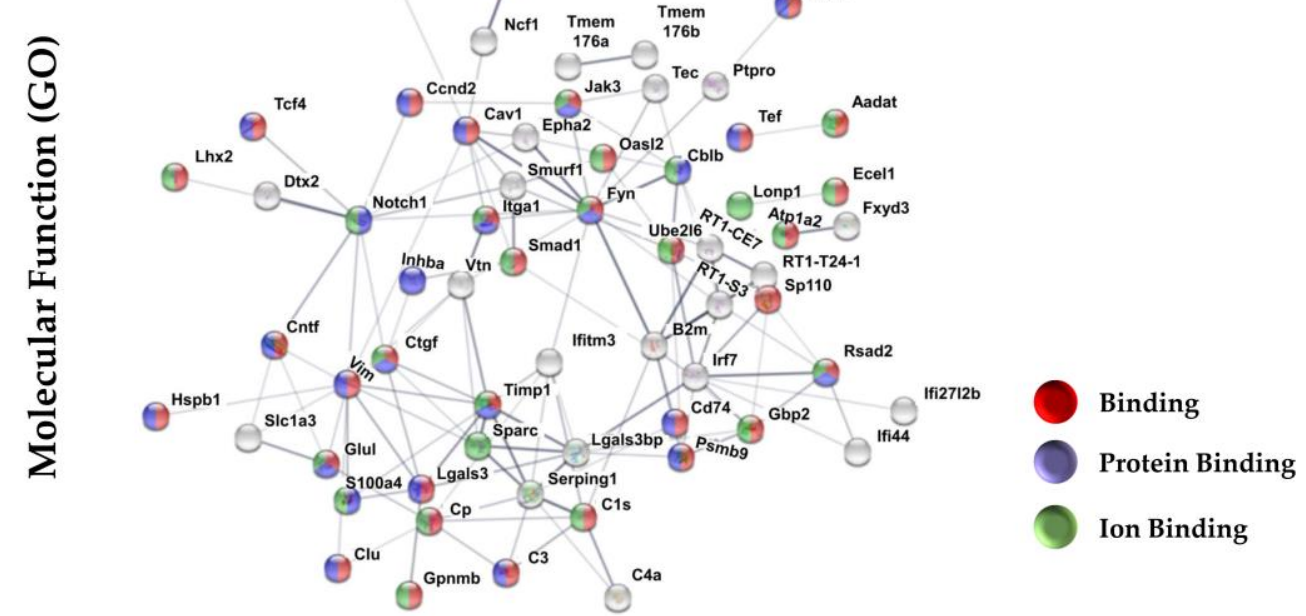

(c)

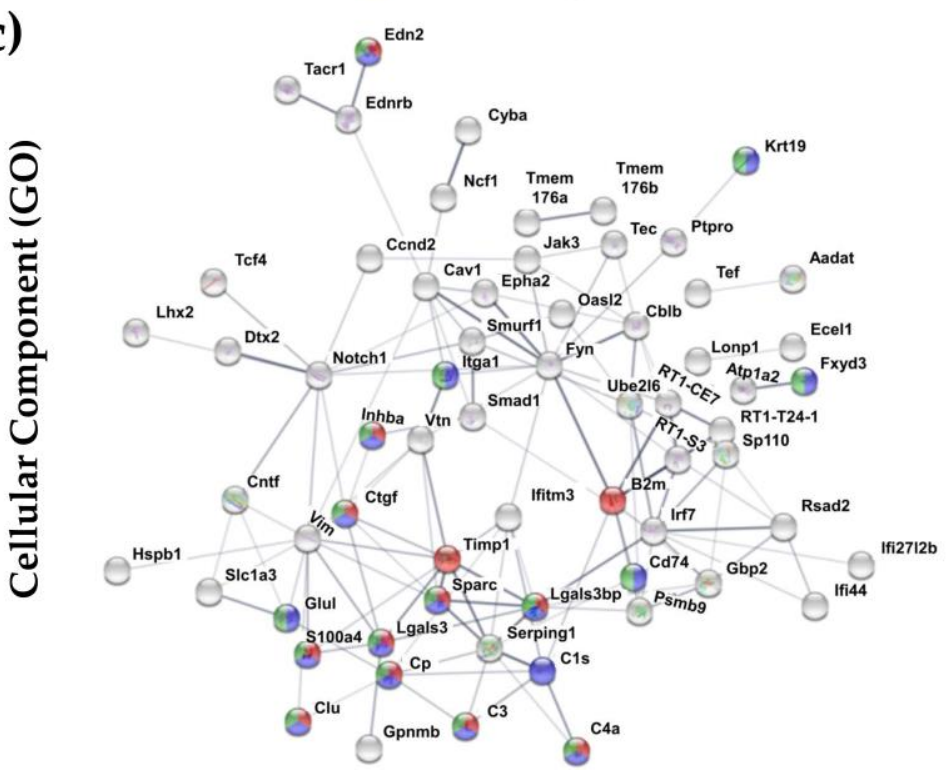

Innate Immune Response

Ion Binding

Figure 3: Protein-protein interaction (PPI) network composed with up-regulated genes after the ONC. The 127 up-regulated genes formed 129 interactions between 64 genes with a confidence 
cutoff of 0.4 , as evidenced by STRING software. Nodes labeled with the encoding gene symbol indicate proteins and the lines represent the corresponding interactions. The confidence score of each interaction is mapped to the line thickness (the thicker the line, the more evidence to support the interaction). The network was then enriched according to Gene Ontology database. The categories of Gene Ontology are depicted: (a) Biological Processes; (b) Molecular Function and (c) Cellular Components and the 3 most significantly enriched categories were used to color the nodes of the interaction networks.

\subsection{ONC alters the stability of gene expression}

In addition to the average expression level, the relative expression variability (REV) among biological replicates provided an important parameter of comparison between CTR and ONC retinas. We found that the REV profile of genes after ONC was very similar to, but with a slight shift towards higher variability than CTR retinas (Figure S1(a) in the Appendix). REV values were then used to estimate the stability of expression (GES) of individual genes in each condition. We found a decrease in the number of very stably expressed genes $(\mathrm{REV}<10)$, from 232 in control retinas to 48 after optic nerve crush. In order to analyze whether the GES values of individual genes were similar between the experimental groups, the GES value for each spot from control retinas was plotted against the GES value for the same spot from ONC retinas (Figure S1(b)). Only a few genes, delimited by the red dotted circles at Figure S1(b), displayed clearly distinct GES values between the two conditions. Panther was used to analyze enrichment of the genes within the red dotted circles (Figure S1(b)) and indicated that most of these genes are related to eye structure and development (Table S8). This result is in agreement with the structural changes in the retina after ONC as expressed by RGC degeneration (Figure 1).

\subsection{Complement cascade and Delta/Notch Pathways are targeted by ONC}

We used the PathVisio3 platform to identify which biological pathways were the most affected among genes up-regulated by ONC. "Complement Cascade Pathway" appeared twice and had the highest Z scores, as well as "Notch-" and "Delta-Notch Signaling Pathways", all related with immune response (Table S6). In addition, many among the top 50 up-regulated genes belong to the Complement cascade and Notch signaling pathways (Table S6). We plotted the results obtained with Pathvisio3 into pathway templates from either the Kyoto Encyclopedia of Genes and Genomes (KEGG) or WikiPathway to visualize significantly altered genes, both up- and down-regulated, in all pathways. We found more significantly up-regulated genes (red), with higher fold-change within the "Complement Cascade Pathway", "Notch-" and "Delta-Notch" signaling pathways (Figure 4, Figure 5 and Figure 6) than within Oxidative Stress and Kit Receptor Signaling Pathway (Figures 7 and 8).

In the "Complement Cascade Pathway", we found no down-regulated genes and five significantly up-regulated genes (red) belonging to both "Classical" and to the "Alternative Pathways": C3 (2.17x), Cfb (2.26x), C1s (2.43x), C4 (2.41x) and Serping1 (3.49x) (Figure 6). Two other genes belonging to the "Membrane Attack Complex" were also up-regulated: vitronectin (1.83x) and clusterin (1.71x) (Figure 6A-B). Next, we examined the number of coordination interactions (synergistic and antagonistic) between gene pairs with significant pairwise Pearson correlation coefficients from the "Complement Cascade Pathway". This analysis allows an estimate of the degree of network interlinkage within the pathway. Expression coordination of two genes may be an indication that the encoded proteins are linked in one or more functional pathways, and therefore their expression levels should be in a particular proportion [60]. Among the control retinas we found 29 positive coordinations ("synergisms") represented by magenta lines in Figure 6A. After the ONC, the number of synergisms raised to 36 , and 2 independent coordinations were found (black dotted 
lines, Figure 6B). For all pathways examined in PathVisio3, no negative coordination ("antagonism") was found, while an increase in positive coordinations was observed following ONC (Figure S1).

We also examined the coordination profiles of all genes from the "Complement Cascade Pathway" against all other genes in our microarray datasets in each experimental condition. Such analysis identifies gene pairs with either similar or opposite coordination profiles, based on the overlap of their synergistically, antagonistically or independently expressed partners. We found that the synergistic coordination among the "Complement Cascade Pathway" genes increased from 21\% in control retina to $36 \%$ after $\mathrm{ONC}$, indicating a stronger alignment of the genes to the network, whereas there were no opposite coordination profiles. As an example, the coordination profiles of the pairs $\mathrm{C} 3-\mathrm{C} 1 \mathrm{qb}$, Serping1-C1qb and Serping1-Vtn are shown in Figure 6C-E. In CTR retinas, the coordination profiles of the paired genes were neutral (black dots), whereas ONC retinas showed a robust increase in similarity (oranges dots), with R2 values of at least 0.9 .

(a)

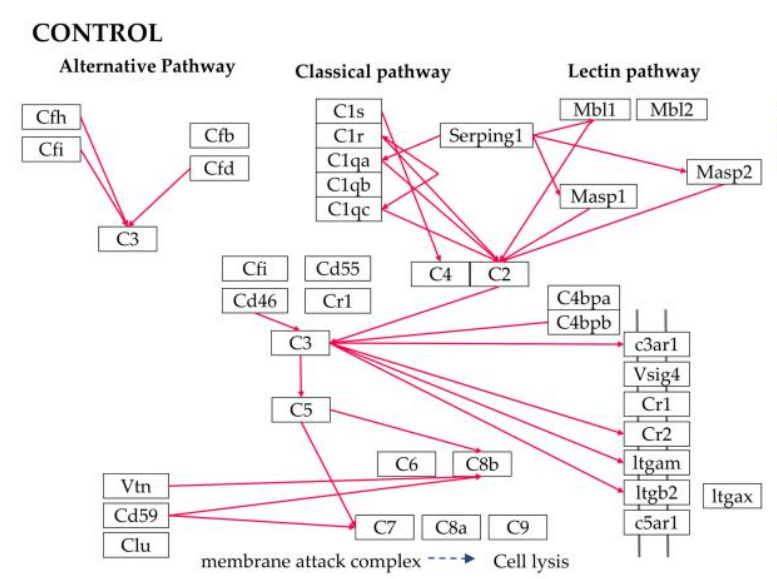

(c)

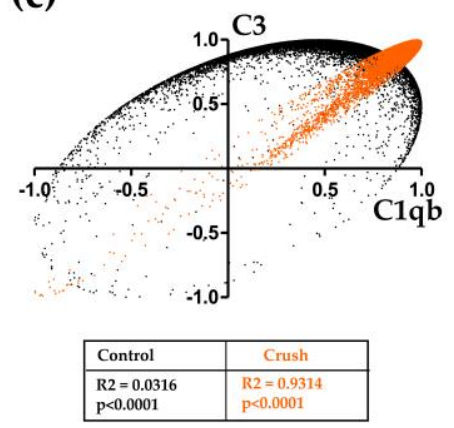

(d)

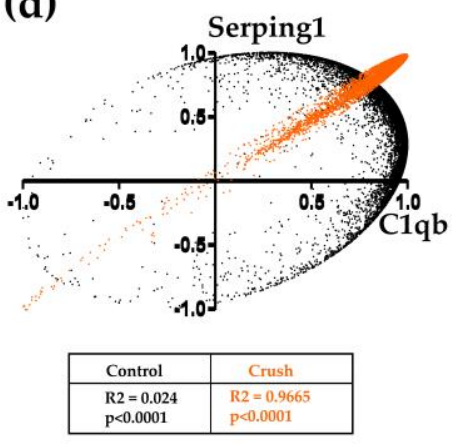

(b)

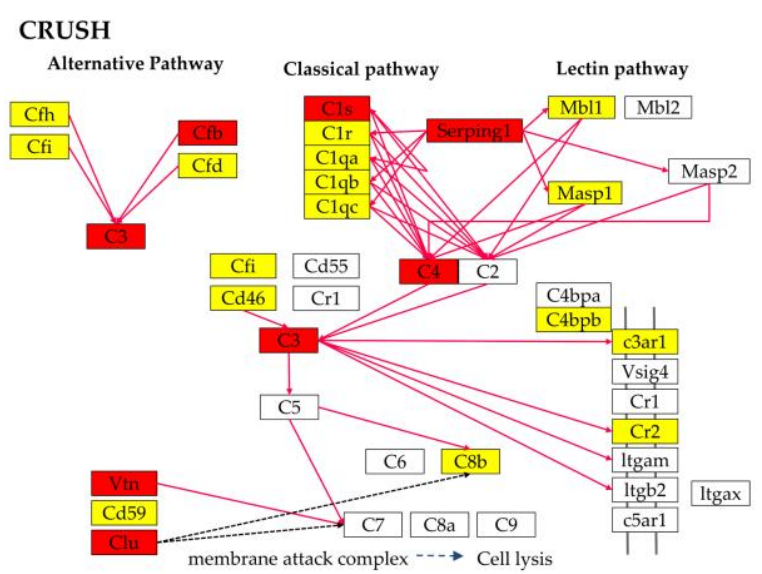

(e)

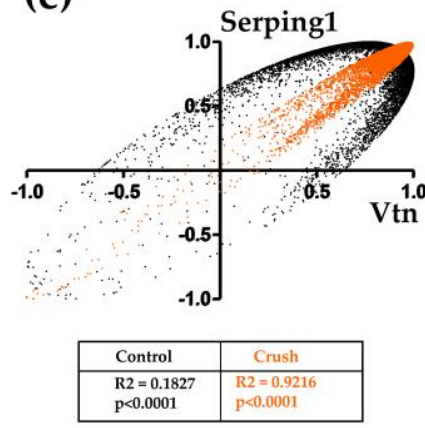

Figure 4: ONC affects the Complement Cascade Pathway. The Complement Cascade pathway obtained from the KEGG platform was used as template to highlight the effect of the ONC in the retinas. Magenta lines in (a) and (b) represent synergistic correlations between pairs of genes and dashed black lines correspond to independent coordination. ONC induced an increase in the number of synergistic correlations. Yellow boxes in (b) indicate genes that showed no significant alteration in ONC versus control retinas, whereas red-filled boxes represent gene up-regulation ( $>1.5$-fold change, $\rho<0.05$ ). White boxes indicate the genes that were absent in the analysis. (c-e) Plots of correlation coefficients between the expression levels of the indicated genes with each other genes differentially expressed in each experimental condition. Note a neutral coordination profile (black dots) for control retinas and a similar profile (orange dots) after ONC.

The "Delta-Notch" and "Notch Signaling Pathways" were also significantly altered by ONC, with five genes up-regulated when compared to control retinas: Cntf (1.55x), Notch1 (1.94x), Fhl1 
(1.53x), Smad1 (2.12x) and Dtx2 (1.51x) (Table 6). The WikiPathway template was used to visualize the altered expression in Notch1 and Deltex2 genes (Figure 7A-B) and the number of coordination interactions between pairs of genes by Pearson's correlations was represented by magenta (synergism) or black dotted (independent coordination) arrows. The number of synergistically expressed gene-pairs increased from 20 in the control condition to 52 after ONC (Figure 7A-B). No independently expressed genes were observed in the ONC dataset. To further assess whether genes in the "Notch Signaling Pathway" are committed to this network, we examined the coordination profiles of genes from this pathway against all other genes in our microarray datasets in each experimental condition. We found an increase of similar coordination from $22 \%$ in CTR retinas to $28 \%$ after ONC. As an example, two neutral profiles (black dots) in the control retinas for the Dll1-Notch1, Dvl3-Dtx3 and Notch4-Notch1 pairs (R2=0.08, 0.18 and 0.63, respectively), changed to similar coordination (orange dots) (R2>0.9) after ONC (Figure 5C-E). These results indicate that ONC induces strong gene networking in the "Notch Signaling pathway".

(a)

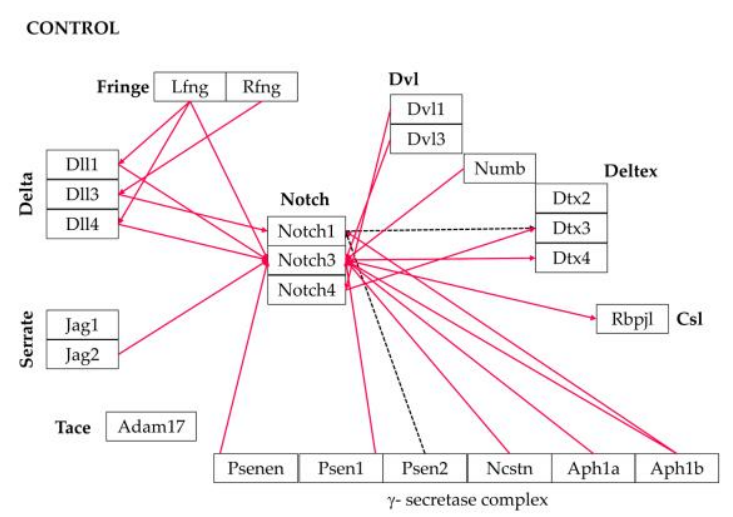

(b)

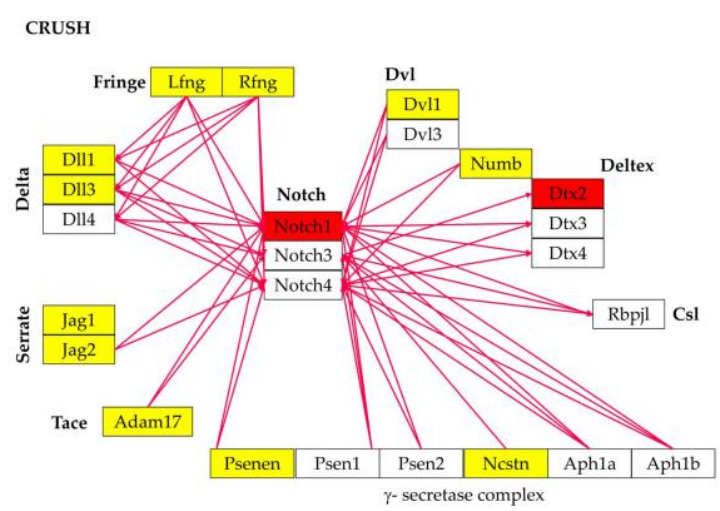

(c)
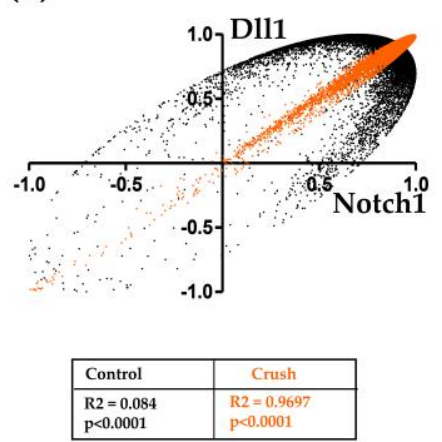

(d)
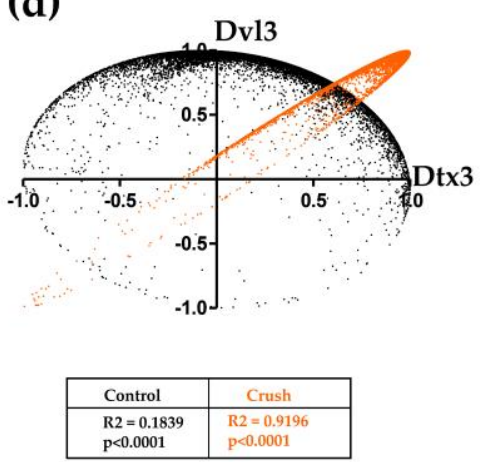

(e)

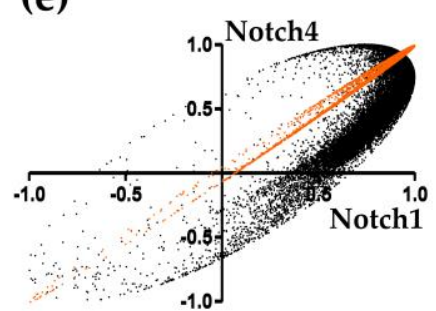

\begin{tabular}{|l|l|}
\hline Control & \multicolumn{1}{|c|}{ Crush } \\
\hline $\mathbf{R} 2=\mathbf{0 . 6 3 5 3}$ & $\mathrm{R} 2=0.9918$ \\
$\mathbf{p}<0.0001$ & $\mathrm{p}<0.0001$ \\
\hline
\end{tabular}

Figure 5: ONC affects the Notch Signaling Pathway. The Notch Signaling pathway was obtained from the Wiki-pathway platform and used as a template to highlight the effect of the ONC in the retinas. Magenta lines in (a) and (b) represent synergistic correlations between pairs of genes and dashed black lines correspond to independent coordination. ONC induced an increase in the number of synergistic correlations. Yellow boxes in (b) indicate genes that showed no significant alteration in ONC versus control retinas, whereas red-filled boxes represent gene up-regulation ( $>1.5$-fold change, $\rho<0.05$ ). White boxes indicate the genes that were absent in the analysis. (c-e) Plots of correlation coefficients between the expression levels of the indicated genes with each other genes differentially expressed in each experimental condition. Note a neutral coordination profile (black dots) for control retinas and a similar profile (orange dots) after ONC. 


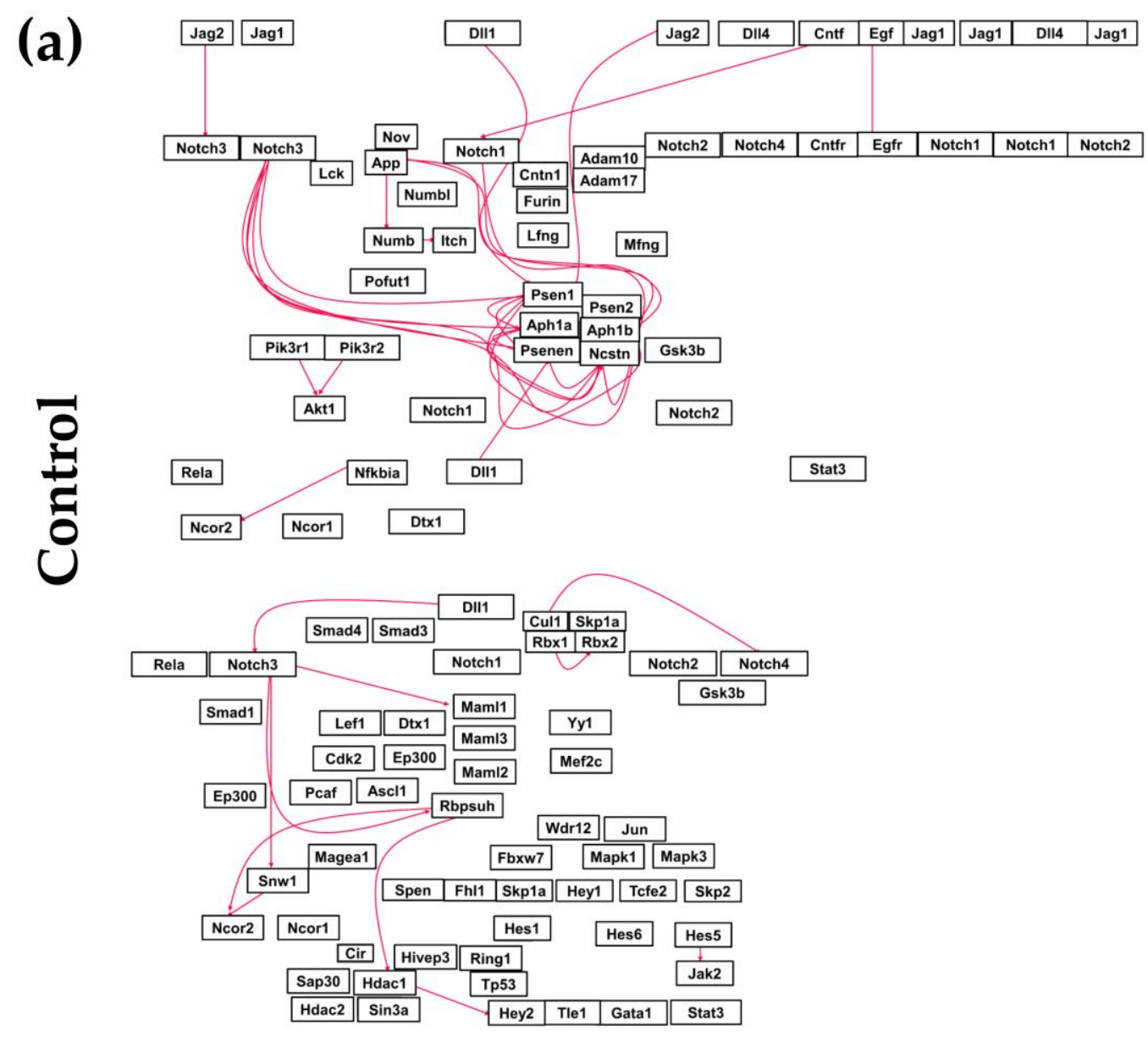

(b)

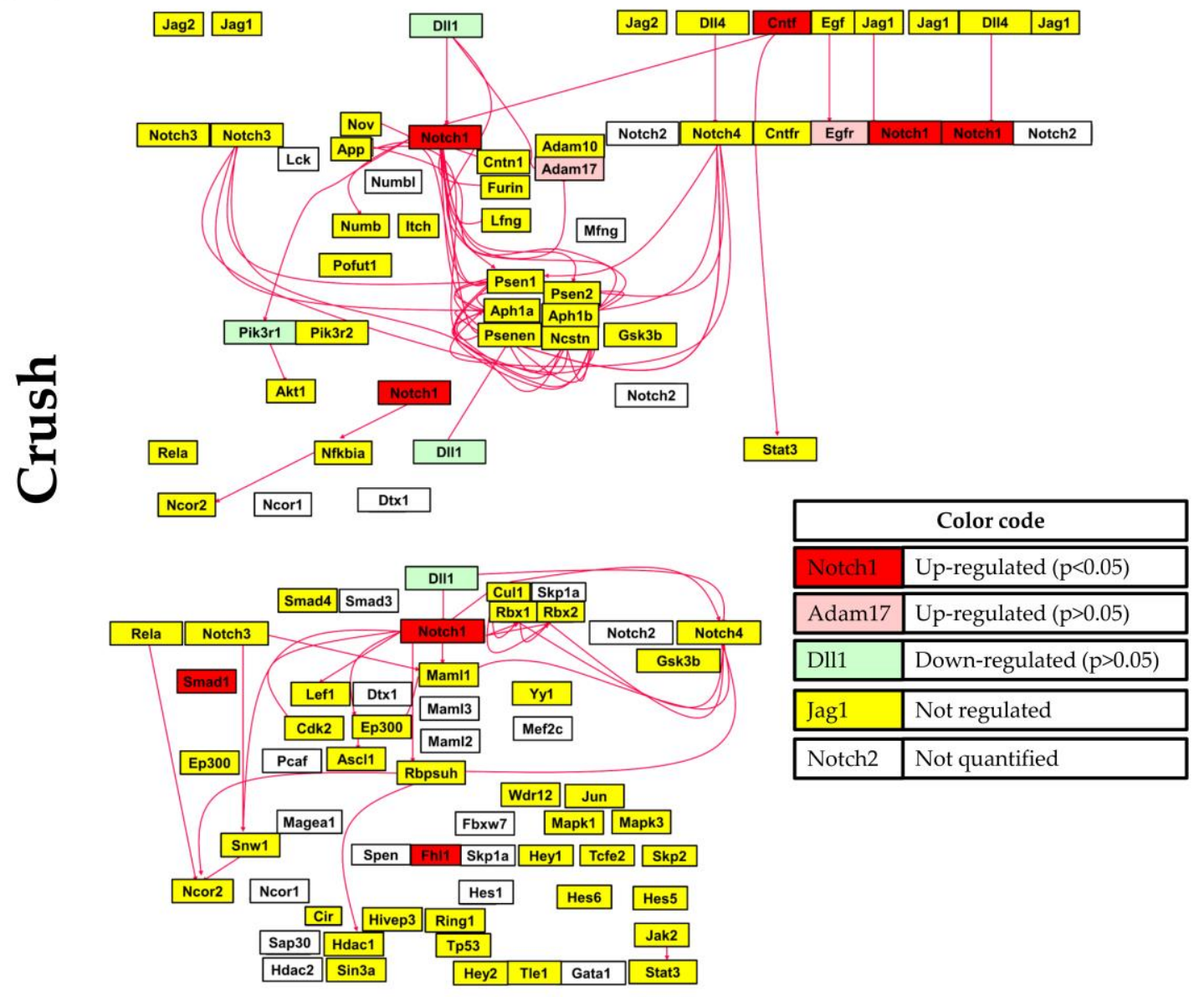


Figure 6: ONC affects the Delta-Notch signaling pathway. This pathway was obtained from the WikiPathway platform and used as a template to highlight the effect of the ONC in the retinas. Magenta lanes represent synergistic correlations between pairs of genes. ONC induced an increase in the number of synergistic correlations. Yellow boxes indicate genes that showed no alteration in ONC versus control retinas, whereas red-filed boxes represent gene up-regulation (>1.5-fold change, $\rho<0.05)$. 


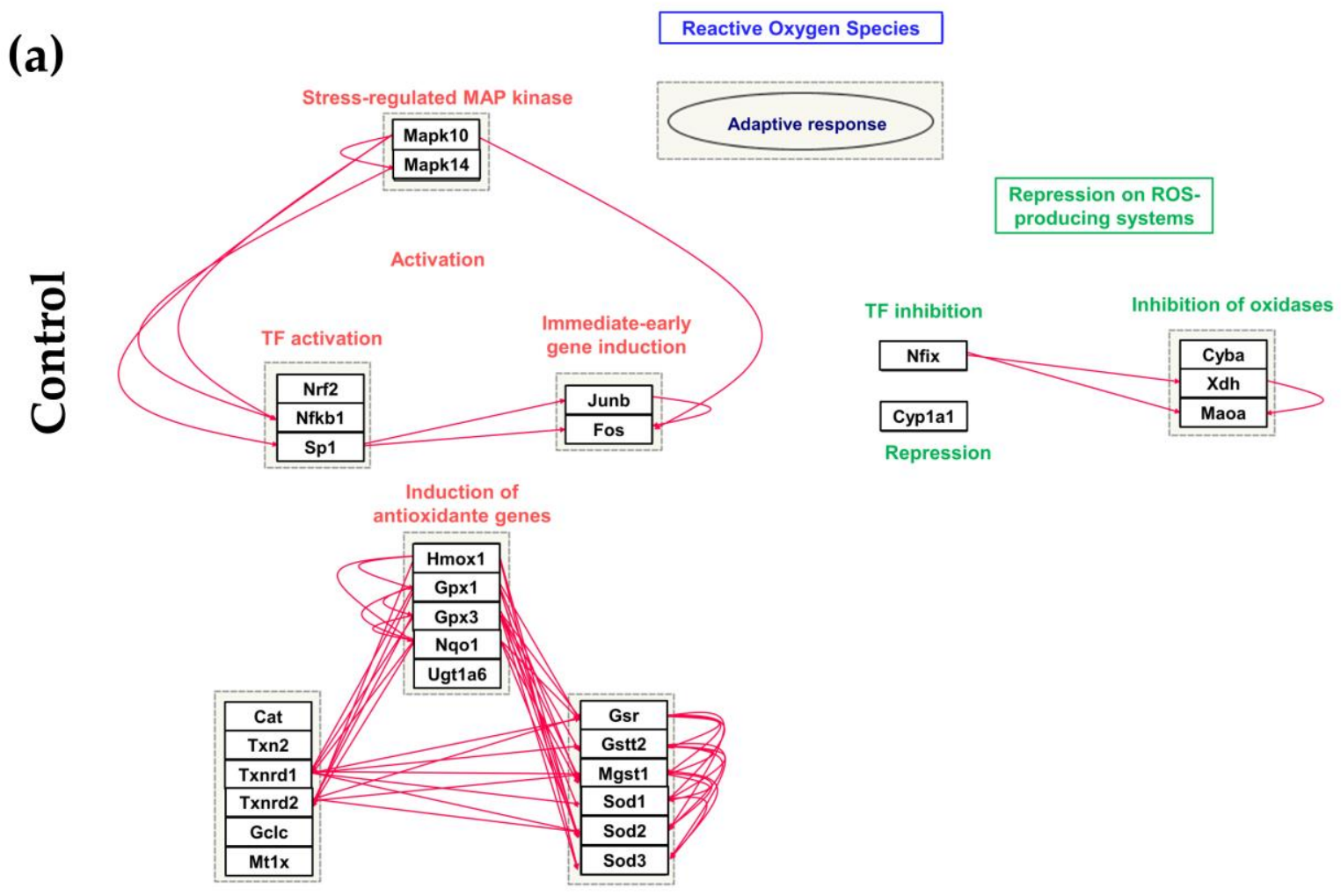

(b)

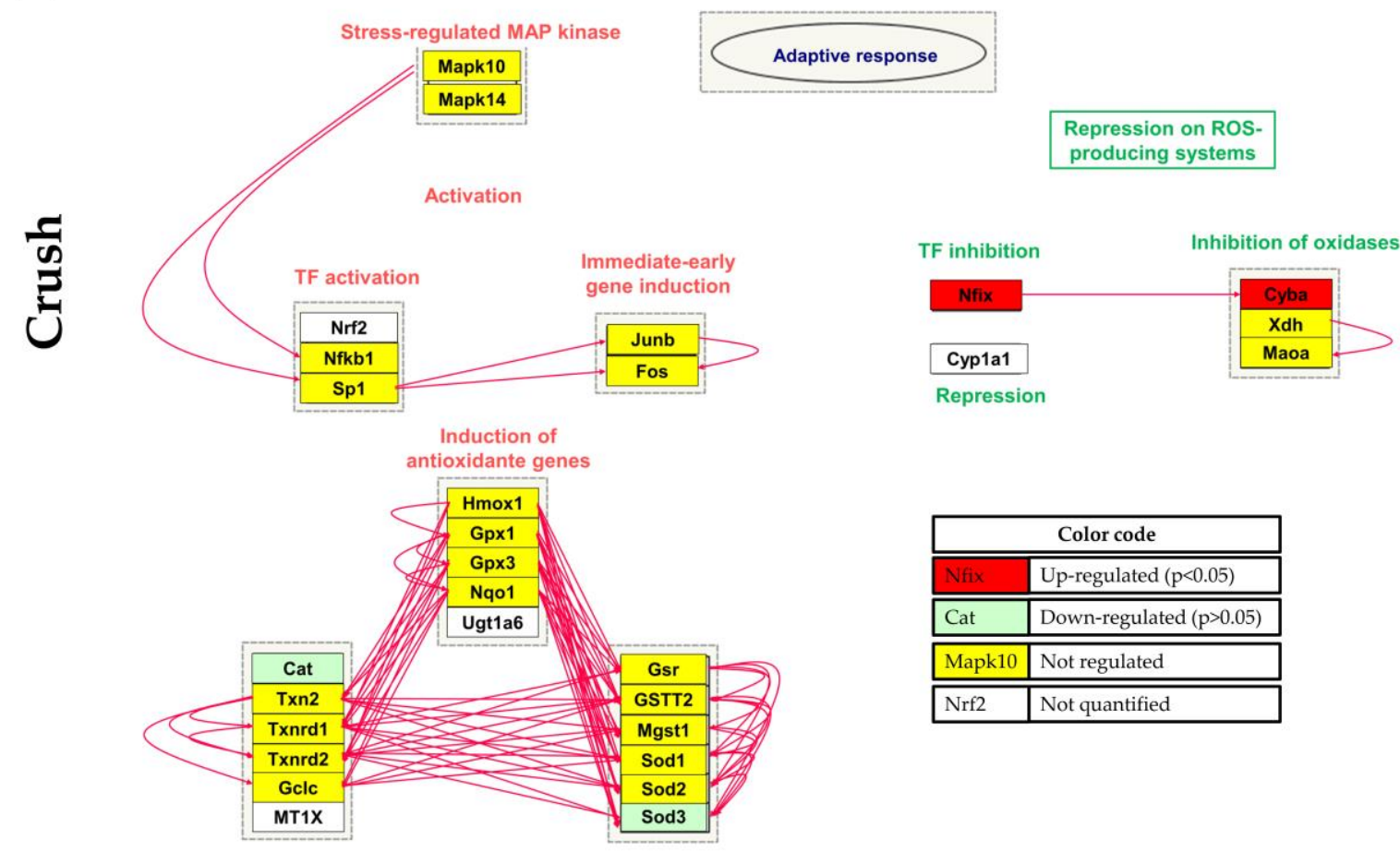

Figure 7: ONC affects the Oxidative Stress. This pathway was obtained from the WikiPathway platform and used as a template to highlight the effect of the ONC in the retinas. Magenta lanes represent synergistic correlations between pairs of genes. ONC induced an increase in the number of synergistic correlations. Yellow boxes indicate genes that showed no alteration in ONC versus control retinas, whereas red-filed boxes represent gene up-regulation $(>1.5$-fold change, $\rho<0.05)$. 


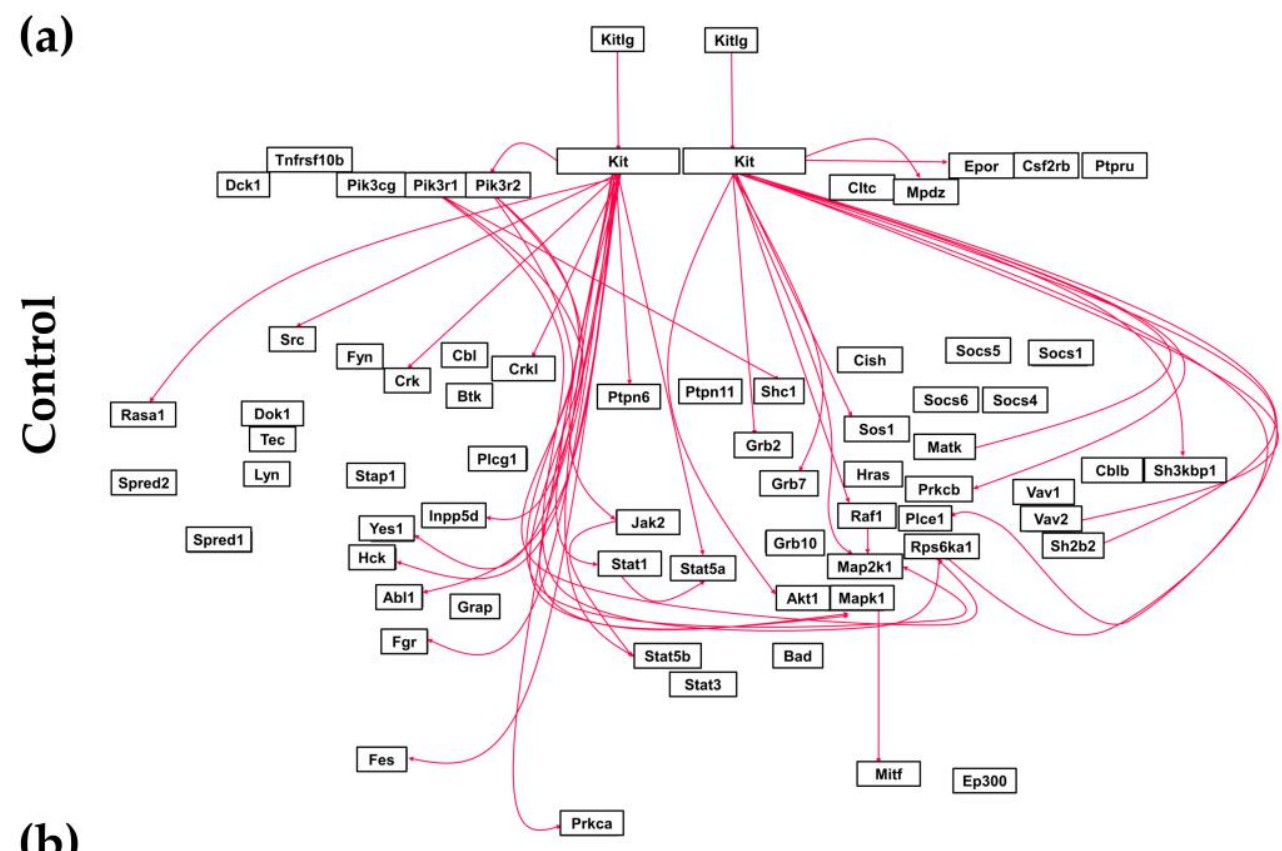

(b)

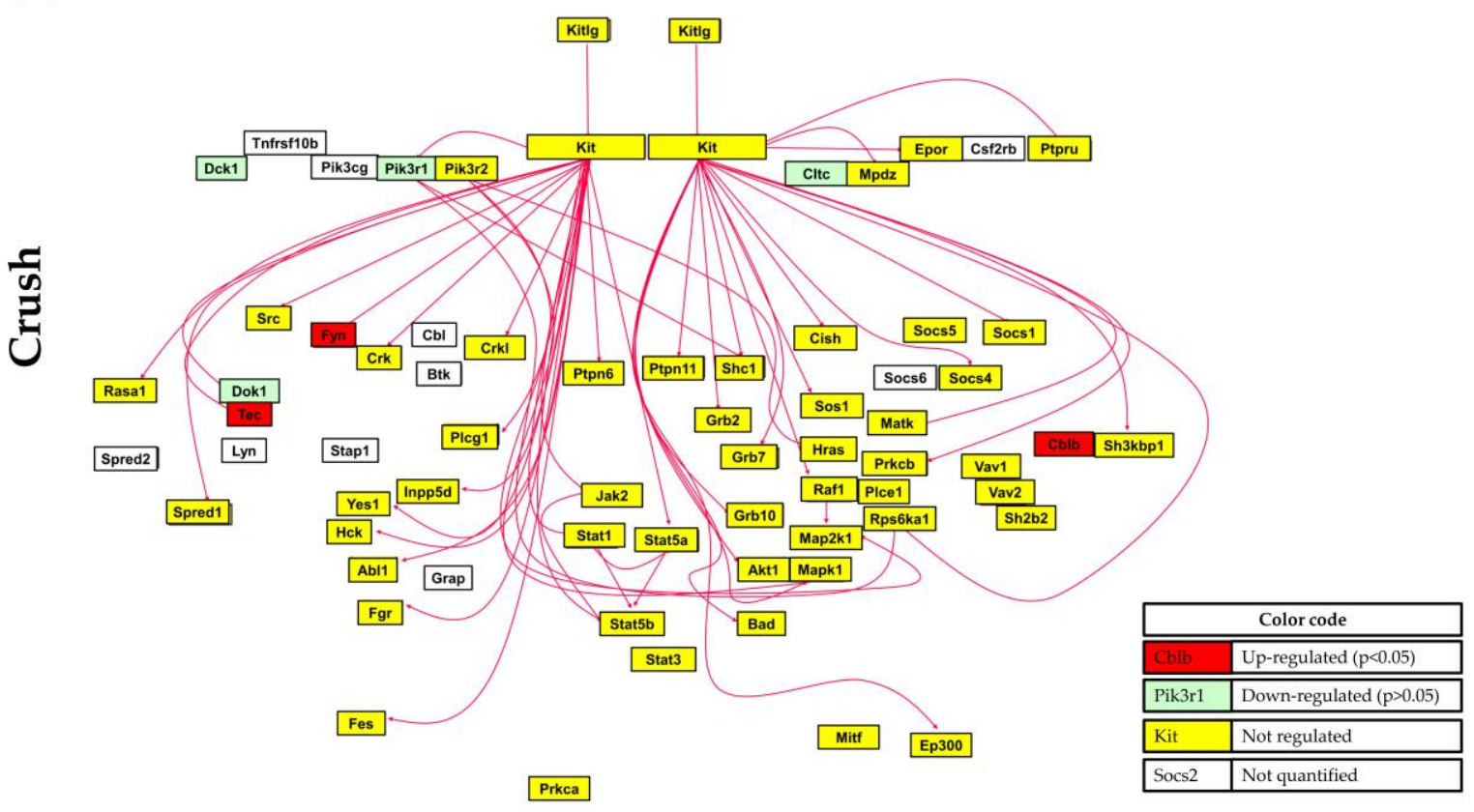

Figure 8: ONC affects the Kit receptor signaling pathway. This pathway was obtained from the WikiPathway platform and used as a template to highlight the effect of the ONC in the retinas. Magenta lanes represent synergistic correlations between pairs of genes. ONC induced an increase in the number of synergistic correlations. Yellow boxes indicate genes that showed no alteration in ONC versus control retinas, whereas red-filed boxes represent gene up-regulation $(>1.5$-fold change, $\rho<0.05)$.

\section{Discussion}

In this study, we conducted a transcriptomic analysis of rat retina at 14 days after ONC, a time-point when the population of retinal ganglion cells was reduced to only $40 \%$. We identified differentially expressed genes, at a total of 127 genes significantly up-regulated, and 66 
down-regulated. We examined changes in gene expression stability and found a reduction in the number of very stably expressed genes from 336 to 124 . Using bioinformatic tools to examine interacting proteins (STRING) and main altered pathways (Pathvisio3), we found that the Complement cascade and Notch signaling pathway were the main affected pathways. Coordination analysis for both pathways showed an increase in the number of synergistically expressed gene pairs and of genes with similar coordination profile.

Our analysis was carried out on whole-retina extracts, and the transcriptome profiles analyzed represent the adaptations of the retinal tissue to the RGC degeneration promoted by the ONC. Although the observed regulation is triggered by the ONC, which leads to RGC death, changes at relative late stages, at 14 days after injury, likely involves the activation of the retinal glia (i.e. astrocytes, Muller cells, and microglial cells), and also other retinal neurons besides RGC, as signs of retinal remodeling. These changes may impact potential treatment strategies to ameliorate the secondary degeneration associated with CNS insults [42].

Unique among transcriptomic studies of the retina is that beyond the regulation of gene expression, we also disclosed relative expression variability, changes in gene expression stability and coordination following ONC. Gene Expression Stability score (GES) ranks the genes according to the strength of the cellular homeostatic mechanisms to keep their expression variability within narrow limits. GES, that includes the most stably expressed genes in the 100th percentile, actually identifies the genes most critical for the survival and phenotypic expression of the cell. By contrast, the most unstably expressed genes (GES in the first percentile) most likely empower the cell to respond/adapt to the environmental fluctuations [53-54]. Moreover, the expression coordination analysis refines the functional pathways, by the identification of gene pairs whose expression fluctuations among biological replicas are positively (synergistically), negatively (antagonistically) or neutrally (independently) correlated. In previous papers [51, 53-54], we have speculated that genes whose encoded proteins are linked in functional pathways should coordinate their expression to optimize a kind of "transcriptomic stoichiometry". Changes in the coordination profiles indicate remodeling of the functional pathways [45; 50-54; 60-62].

Expression of individual genes depends on local conditions that, although similar, are not identical among biological replicas. We assume that expression of key genes is kept by the cellular homeostatic mechanisms within narrow intervals while that of non-key genes is less restrained to readily adapt to environmental changes. In our results we found a higher variability in the REV profile of genes with ONC (Figure 6A), as expected in pathological conditions, suggesting that control mechanisms are also affected.

Thus, by analyzing GES changes following the crush of the optic nerve, we found clues about retina cells changing priorities in controlling the expression level of certain genes. Our results identified, at 14 days after ONC, that only a few genes presented an altered profile in their GES, with enrichment in genes of eye structure (Supplementary Table 1). Particularly, crystallin genes underwent a dramatic change in their GES, from stable expression in control sample (GES > 60) to a very unstable expression (GES $<6$ ), indicating active participation in the retinal changes at 14 days after ONC. The crystallin genes have chaperone-like properties involved in an increase of cellular resistance to stress-induced apoptosis [63]. Up-regulation and down-regulation of crystallin expression has been reported upon different cellular stresses, and those alterations are viewed as a cellular response against environmental and metabolic insults [64-66]. Crystallins have been related with both retinal ganglion cells [67] and amacrine cells [68], supporting its active participation in the remodeling of retinal tissue after injury, possibly through a decrease in resistance to stress, as well as leading to tissue stabilization. Curiously, two other genes presented a drastic change in GES: Adad2 $($ GES $(C T R)=79$ to GES $($ ONC) $=5$ ), a gene related with RNA editing [69], and RGD1308160 (GES $(\mathrm{CTR})=61$ to GES $(\mathrm{ONC})=10)$, a gene that, according to BlastP, has a loose homology with the C. elegans gene smc-4, involved in chromosome stabilization [70]. These data suggest that both such mechanisms are very active at 14 days after ONC.

Typical RGC-expressed genes, underrepresented in ONC retinas compared to control (Figure $3 \mathrm{~A})$, reflect RGC death after optic nerve damage. Among the 66 downregulated genes, $20 \%$ have 
been described as expressed by ganglion cells [5-6; 21]. Enrichment analysis of the down-regulated genes showed cytoskeletal organization as the main biological process, with genes of intermediary filaments and of proteins that interact with them. Neurofilaments are particularly abundant in axons, and essential for their growth, maintenance of caliber, transmission of electrical impulses, velocity of impulse conduction, as well as regulation of enzymes function and the structure of linker proteins [71-73].

Additional biological roles have been attributed to neurofilaments such as synaptic plasticity. Marked decrease in the expression of the neurofilament genes was first shown in brain tissue from Alzheimer's disease patients as compared to controls [74]. It is generally accepted that CNS disorders are divided between early and late changes, associated with dysfunction of neuronal activity caused by perturbations of synapses [75]. Neural reorganization after stroke is initiated as cellular reactions to degeneration. While neurons die in an ischemic region, axons and synapses degenerate in further brain regions, promoting regenerative responses that lead the growth of new connections among surviving neurons [76]. Retinal ganglion cell dendritic arbors also showed significant reduction after 2 weeks of elevation of intraocular pressure, a common model of chronic glaucoma [77]. In a primate glaucoma model, a correlation was established between abnormalities of parasol RGC dendrite morphology and function [78]. Morphological changes of RGC dendritic arbors have been detected before axon thinning or soma shrinkage, suggesting that dendritic abnormalities may precede degeneration of other ganglion cell domains. Alterations of neurofilament expression in various neurological disorders not only underlie axonopathy, but also synaptic remodeling because of its vital roles in synaptic function [79-80]. Since at 14 days after ONC the retinal tissue still harbors $40 \%$ of the RGC, the decreased expression of genes related with cytoskeletal organization, as intermediary filaments, may be representative of retinal remodeling, not restricted to the injured axon but also at the level of dendrites.

Many components of the innate immune system are expressed intrinsically by retinal cells (Retinal Database, GeneNetwork.org), and innate immune networks are activated by various types of insults to the retina, such as ONC, partial transection of the optic nerve, DBA2J mouse models of glaucoma, among others $[6 ; 10 ; 15 ; 21 ; 81-83]$. In the present study, enrichment analysis disclosed the Complement cascade as the most prominent biological process among differentially expressed genes after ONC (Table 6)) and was up-regulated in the retina as early as 2 days after ONC [84]. Such activation, specifically including C1q, C3, and Cfi [20], suggests that the innate immune system plays an important role in the immune-privileged environment of the retina through glia cells, and specifically in the response of the retina to injuries. It has been suggested that, at an early stage of a mouse glaucoma model, the complement cascade mediates synapse loss, in particular C3 [85-88]. At late stage glaucoma, the Complement cascade is thought to play its traditional role of opsonizing and removing the cellular debris from widespread RGC death [89]. Recently, it was described that C1q marks a subset of RGC in the embryonic retina and that knockout of C3 receptor, which is only found in microglia, resulted in increased RGC numbers, indicating a direct relationship with microglia-mediated RGC elimination [90]. To date, inflammation has been considered secondary to the tissue damage, and is now thought to be part of a protective response of the immune system. It is also believed that an intermediate stage exists between basal homeostatic conditions and true inflammation [91].

Our data showed that ONC leads to an increase in synergistic coordination, most evident in the classic pathway of complement cascade, which indicates a stronger gene network in this pathway. It is particularly interesting that the serping1 gene showed increased synergistic coordination at 14 days after ONC (Figure 7). Serping1 is a $\mathrm{C} 1$ inhibitor known to block the initiation of the complement cascade through the classical pathway, therefore limiting inflammation. It is indirectly involved in the production of bradykinin, a peptide that promotes inflammation by increasing the permeability of blood vessel walls and also inhibits leukocyte recruitment into ischemic cardiac tissue, an effect independent of protease inhibition [92]. Therefore, the up-regulation of serping1 in ONC retinas may help control the inflammatory response after injury, both by modulation of the 
complement cascade, as well as preventing infiltration of peripheral inflammatory cells through the blood-retina barrier.

Our enrichment analysis also showed up-regulation of the Notch signaling pathway at 14 days after ONC. Notch signaling is known to play important roles during retinal development, in both retinal ganglion cell differentiation [93] and proliferation of Müller glia in acutely damaged chick retina [94]. Notch is expressed in most Müller glia cells at low levels in undamaged retina, and blockade of notch activity prior to damage is protective to amacrine, bipolar and ganglion cells [95]. Also, overexpression of notch1 has been observed in several neurodegenerative diseases [96-97]. Besides notch, the deltex2 gene was also up regulated (Figure 8). A recent study showed that Dtx together with its interacting partner, Hrp48, down-regulated Notch signaling and induced cell death during Drosophila development [98]. At 14 days after ONC, the up-regulation of both notch and deltex2 suggests that notch signaling may act upon retinal Müller cells via a non-canonical pathway, thereby positively influencing RGC degeneration.

\section{Conclusions}

In summary, our data indicate that ONC induces a robust, long-lasting alteration of two main pathways, including a significant increase in the expression and coordination of inflammation-related genes. The coordination analyses of genes within each pathway and with the entire transcriptome suggest that such biological pathways may act after ONC as major players in changes of gene expression that lead to both degeneration and remodeling of retinal tissue. Further functional studies on the effects of these genes are warranted to clarify their roles in molecular mechanisms within the retinal tissue after damage to the optic nerve.

Supplementary Materials: The following are available online at www.mdpi.com/xxx/s1, Figure S1: ONC affect the expression variability; Table S1: Previously described RGC markers downregulated in ONC vs CTR, Table S2: Enrichment analysis with genes had a dramatic change in their expression stability after ONC.

\section{All tables here in editable format (word not pdf)}

Author Contributions: Conception and design: R.L.; H.P.S.; D.A.; Development of methodology: C.M.; D.C. S.; D.A.I.; S.I.; Acquisition of data (provided tissue, extract total RNA and performed microarray experiment, provided facilities, etc.): H.P.S.; D.A.; S.I.; D.A.I.; Analysis and interpretation of data (e.g., statistical analysis, biostatistics, computational analysis): D.A.I.; H.P.S.; D.A.; P.H.V.; R.L.; Writing, review, and/or revision of the manuscript: H.P.S.; D.A.; R.L.; P.H.V.; D.C.S.; D.A.I.; Study supervision: H.P.S.; D.A.; R.L. All authors read and approved the final manuscript..

Funding: This study was financed in part by the Coordenação de Aperfeiçoamento de Pessoal de Nível Superior - Brasil (CAPES) - Finance Code 001; CNPq and FAPERJ. D.A.I. was supported by the Chancellor's Research Initiative (CRI) funding for the Center for Computational Systems Biology at the Prairie View A\&M University. D.A. was supported by CNPq (grant numbers 44447878/2014-0 and 401772/2015-2) and by Fundação Oswaldo Cruz (Fiocruz), through the INOVA Fiocruz program, grant number 3231984391; D.C.S. was supported by NIH grant number NS092466.

Acknowledgments: We would like to thank José Nilson dos Santos, Daianne Neves Mandarino Torres, José Francisco Tibúrcio and Gildo Brito de Souza at Universidade Federal do Rio de Janeiro for technical support; Mrs. Heloisa Diniz from the Department of Image Production and Processing (Serviço de Produção e Tratamento de Imagem - IOC) at the Oswaldo Cruz Institute for help with the figures.

Conflicts of Interest: The authors declare no conflict of interest. The funders had no role in the design of the study; in the collection, analyses, or interpretation of data; in the writing of the manuscript, or in the decision to publish the results.

\section{References}

1. Foster P.J.; Buhrmann R.; Quigley H.A.; Johnson G.J. The definition and classification of glaucoma in prevalence surveys. Br J Ophthalmol 2002, 86(2):238-42. DOI: 10.1136/bjo.86.2.238. 
2. Johnson T.V.; Tomarev S.I. Rodent models of glaucoma. Brain Res Bull 2010, 15;81(2-3):349-58. DOI: 10.1016/j.brainresbull.2009.04.004.

3. Ishikawa M.; Yoshitomi T.; Zorumski C.F.; Izumi Y. Experimentally Induced Mammalian Models of Glaucoma. Biomed Res Int 2015, 281214. DOI: 10.1155/2015/281214.

4. Harada C.; Kimura A.; Guo X.; Namekata K.; Harada T. Recent advances in genetically modified animal models of glaucoma and their roles in drug repositioning. Br J Ophthalmol 2019, 103(2):161-166. DOI: 10.1136/bjophthalmol-2018-312724.

5. Rheaume B.A.; Jereen A.; Bolisetty M.; Sajid M.S.; Yang Y.; Renna K.; Sun L.; Robson P.; Trakhtenberg E.F. Single cell transcriptome profiling of retinal ganglion cells identifies cellular subtypes. Nat Commun 2018, 17;9(1):2759. DOI: 10.1038/s41467-018-05134-3.

6. Wang D.Y.; Ray A.; Rodgers K.; Ergorul C.; Hyman B.T.; Huang W.; Grosskreutz C.L. Global gene expression changes in rat retinal ganglion cells in experimental glaucoma. Invest Ophthalmol Vis Sci 2010, 51(8):4084-95. DOI: 10.1167/iovs.09-4864.

7. Fasano M.; Monti C.; Alberio T. A systems biology-led insight into the role of the proteome in neurodegenerative diseases. Expert Rev Proteomics 2016, 13(9):845-55. DOI: 10.1080/14789450.2016.1219254.

8. Saleh R.; Karpe A.; Zinkernagel M.S.; Munk M.R. Inner retinal layer change in glaucoma patients receiving anti-VEGF for neovascular age related macular degeneration. Arch Clin Exp Ophthalmol 2017, 255(4):817-824. DOI: 10.1007/s00417-017-3590-4.

9. Vien L.; DalPorto C.; Yang D. Retrograde Degeneration of Retinal Ganglion Cells Secondary to Head Trauma. Optom Vis Sci 2017, 94(1):125-134. DOI: 10.1097/OPX.0000000000000899.

10. Graefes Chiha W.; LeVaillant C.J.; Bartlett C.A.; Hewitt A.W.; Melton P.E.; Fitzgerald M.; Harvey A.R. Retinal genes are differentially expressed in areas of primary versus secondary degeneration following partial optic nerve injury. PLoS One 2018, 9;13(2): e0192348. DOI: 10.1371/journal.pone.0192348.

11. McCurley A.T.; Callard G.V. Time course analysis of gene expression patterns in zebrafish eye during optic nerve regeneration. J Exp Neurosci 2010, 4:17-33. PMID: 20740047.

12. Whitworth G.B.; Misaghi B.C.; Rosenthal D.M.; Mills E.A.; Heinen D.J.; Watson A.H.; Ives C.W.; Ali S.H.; Bezold K.; Marsh-Armstrong N.; Watson F.L. Translational profiling of retinal ganglion cell optic nerve regeneration in Xenopus laevis. Dev Biol 2017, 15;426(2):360-373. DOI: 10.1016/j.ydbio.2016.06.003.

13. Kompass K.S.; Agapova O.A.; Li W.; Kaufman P.L.; Rasmussen C.A.; Hernandez M.R. Bioinformatic and statistical analysis of the optic nerve head in a primate model of ocular hypertension. BMC Neurosci 2008, 9:93-114. DOI: 10.1186/1471-2202-9-93.

14. Steele M.R.; Inman D.M.; Calkins D.J.; Horner P.J.; Vetter M.L. Microarray Analysis of Retinal Gene Expression in the DBA/2J Model of Glaucoma. Invest Ophthalmol. Vis. Sci 2006, 47:977-985. DOI: 10.1167/iovs.05-0865.

15. Ahmed F.; Brown K.M.; Stephan D.A.; Morrison J.C.; Johnson E.C.; Tomarev S.I. Microarray Analysis of Changes in mRNA Levels in the Rat Retina after Experimental Elevation of Intraocular Pressure. Invest Ophthalmol Vis Sci 2004; 45:1247-1258. DOI: 10.1167/iovs.03-1123.

16. Wang D.Y.; Ray A.; Rodgers K.; Ergorul C.; Hyman B.T.; Huang W.; Grosskreutz C.L. Global Gene Expression Changes in Rat Retinal Ganglion Cells in Experimental Glaucoma. Invest Ophthalmol Vis Sci 2010, 51:4084-4095. DOI: 10.1167/iovs.09-4864.

17. Vázquez-Chona F.; Song B.K.; Geisert Jr E.E. Temporal Changes in Gene Expression after Injury in the Rat Retina. Invest Ophthalmol Vis Sci 2004, 45(8):2737-2756. DOI: 10.1167/iovs.03-1047.

18. Piri N.; Kwong J.M.K.; Song M.; Elashoff, D.; Caprioli J. Gene expression changes in the retina following optic nerve transection. Molecular Vision 2006, 12:1660-73. PMID: 17200666.

19. Kamphuis W.; Dijk F.; van Soest S.; Bergen, A.A. Global gene expression profiling of ischemic preconditioning in the rat retina. Mol. Vis 2007, 28;13:1020-30. PMCID: PMC2776543.

20. Howell G.R.; Macalinao D.G.; Sousa G.L.; Walden M.; Soto I.; Kneeland S.C.; Barbay J.M.; King B.L.; Marchant J.K.; Hibbs M.; Stevens B.; Barres B.A.; Clark A.F.; Libby R.T.; John S.W. Molecular clustering identifies complement and Endothelin induction as early events in a mouse model of glaucoma. J. Clin. Invest 2011, 121:1429-1444. DOI: 10.1172/JCI44646.

21. Guo Y.; Johnson E;C.; Cepurna W.O.; Dyck J.A.; Doser T.; Morrison J.C. Early Gene Expression Changes in the Retinal Ganglion Cell Layer of a Rat Glaucoma Model. Invest Ophthalmol Vis Sci 2011, 52(3):1460-73. DOI: 10.1167/iovs.10-5930. 
22. Chiha W.; LeVaillant C.J.; Bartlett C.A.; Hewitt A.W.; Melton P.E.; Fitzgerald M.; Harvey A.R. Retinal genes are differentially expressed in areas of primary versus secondary degeneration following partial optic nerve injury. PLoS One 2018, 13(2): e0192348. DOI: 10.1371/journal.pone.0192348.

23. Yang Z.; Quigley H.A.; Pease M.E.; Yang Y.; Qian J.; Valenta D.; Zack D.J. Changes in Gene Expression in Experimental Glaucoma and Optic Nerve Transection: The Equilibrium between Protective and Detrimental Mechanisms. Invest Ophthalmol Vis Sci 2007, 48(12):5539-48. DOI: 10.1167/iovs.07-0542.

24. Yoshimura N.; Kikuchi T.; Kuroiwa S.; Gaun S. Differential temporal and spatial expression of immediate early genes in retinal neurons after ischemia-reperfusion injury. Invest. Ophthalmol. Vis. Sci 2003, 44:2211-2220. DOI: 10.1167/iovs.02-0704.

25. Ahmed F.; Brown K.M.; Stephan D.A.; Morrison J.C.; Johnson E.C.; Tomarev S.I. Microarray analysis of changes in mRNA levels in the rat retina after experimental elevation of intraocular pressure. Invest. Ophthalmol. Vis. Sci 2004, 45:1247-58. DOI: 10.1167/iovs.03-1123.

26. Wilson A.S.; Hobbs B.G.; Shen W.Y.; Speed T.P.; Schmidt U.; Begley C.G.; Rakoczy P.E. Argon laser photocoagulation-induced modification of gene expression in the retina. Invest Ophthalmol Vis Sci 2003, 44:1426-34. DOI: 10.1167/iovs.02-0622.

27. Chen L.; Wu W.; Dentchev T.; Zeng Y.; Wang J.; Tsui I.; Tobias J.W.; Bennett J.; Baldwin D.; Dunaief J.L. Light damage induced changes in mouse retinal gene expression. Exp Eye Res 2004, 79:239-47. DOI: 10.1016/j.exer.2004.05.002.

28. Vazquez-Chona F.; Song B.K.; Geisert E.E. Jr. Temporal changes in gene expression after injury in the rat retina. Invest. Ophthalmol. Vis. Sci 2004, 45:2737-46. DOI: 10.1167/iovs.03-1047.

29. Agudo M.; Pérez-Marín M.C.; Sobrado-Calvo P.; Lonngren U.; Salinas-Navarro M.; Cánovas I.; Nadal-Nicolás F.M. Miralles-Imperial J.; Hallböok F.; and Vidal-Sanz M. Immediate up-regulation of proteins belonging to different branches of the apoptotic cascade in the retina after optic nerve transection and optic nerve crush. Invest. Ophthalmol. Vis. Sci 2009, 50:424-431. DOI: 10.1167/iovs.08-2404.

30. Grimm C.; Wenzel A.; Hafezi F.; Reme C.E. Gene expression in the mouse retina: the effect of damaging light. Mol Vis 2000, 6:252-260. PMID: 11134582.

31. Yoshimura N.; Kikuchi T.; Kuroiwa S.; Gaun S. Differential temporal and spatial expression of immediate early genes in retinal neurons after ischemia-reperfusion injury. Invest. Ophthalmol. Vis. Sci 2003, 44:2211-2220. DOI: 10.1167/iovs.02-0704.

32. Yasuda M.; Tanaka Y.; Ryu M.; Tsuda S.; Nakazawa T. RNA sequence reveals mouse retinal transcriptome changes early after axonal injury. PLoS One 2014, 9(3):e93258. DOI: 10.1371/journal.pone.0093258.

33. Frebel K.; Wiese S. Signalling molecules essential for neuronal survival and differentiation. Biochem. Soc. Trans 2006, 34:1287-90. DOI: 10.1042/BST0341287.

34. Agudo M.; Pérez-Marín M.C.; Lönngren U.; Sobrado-Calvo P.; Conesa A.; Cánovas I.; Salinas-Navarro M.; Miralles-Imperial J.; Hallböok F. and Vidal-Sanz M. Time course profiling of the retinal transcriptome after optic nerve transection and optic nerve crush. Molecular Vision 2008, 14:1050-1063. PMCID: PMC2426719.

35. Sharma T.P.; McDowell C.M.; Liu Y.; Wagner A.H.; Thole D.; Faga B.P.; Wordinger R.J.; Braun T.A.; Clark A.F. Optic nerve crush induces spatial and temporal gene expression patterns in retina and optic nerve of BALB/cJ mice. Mol. Neurodegeneration 2014, 9:14-19. DOI: 10.1186/1750-1326-9-14.

36. Piri N.K.J.M.; Song M.; Elashoff D.; Caprioli J. Gene expression changes in the retina following optic nerve transection. Mol Vis 2006, 12:1660-73. PMID: 17200666.

37. Yang Z.; Quigley H.A.; Pease M.E.; Yang Y.; Qian J.; Valenta D.; Zack D.J. Changes in gene expression in experimental glaucoma and optic nerve transection: the equilibrium between protective and detrimental mechanisms. Invest Ophthalmol Vis Sci 2007, 48(12):5539-48. DOI: 10.1167/iovs.07-0542.

38. Guo Y.; Cepurna W.O.; Dyck J.A.; Doser T.A.; Johnson E.C.; Morrison J.C. Retinal cell responses to elevated intraocular pressure: a gene array comparison between the whole retina and retinal ganglion cell layer. Invest Ophthalmol Vis Sci 2010, 51(6):3003-18. DOI: 10.1167/iovs.09-4663.

39. Grozdanic S.D.; Lazic T.; Kuehn M.H.; Harper M.M.; Kardon R.H.; Kwon Y.H.; Lavik E.B.; Sakaguchi D.S. Exogenous modulation of intrinsic optic nerve neuroprotective activity. Graefes Arch Clin Exp Ophthalmol 2010, 248(8):1105-16. DOI: 10.1007/s00417-010-1336-7.

40. Guo Y.; Johnson E.C.; Cepurna W.O.; Dyck J.A.; Doser T.; Morrison J.C. Early gene expression changes in the retinal ganglion cell layer of a rat glaucoma model. Invest Ophthalmol Vis Sci 2011, 52(3):1460-73. DOI: 10.1167/iovs.10-5930. 
41. Parrilla-Reverter G.; Agudo M.; Nadal-Nicolás F.M.; Alarcón-Martínez L.; Jiménez-López M.; Salinas-Navarro M.; Sobrado-Calvo P.; Bernal-Garro J.M.; Villegas-Pérez M.P.; Vidal-Sanz M. Time-course of the retinal nerve fibrer layer degeneration after complete intra-orbital optic nerve transection or crush: a comparative study. Vision Res 2009, 49(23):2808-25. DOI: 10.1016/j.visres.2009.08.020.

42. Calkins D.J. Critical pathogenic events underlying progression of neurodegeneration in glaucoma. Prog Retin Eye Res 2012, 31(6):702-19. DOI: 10.1016/j.preteyeres.2012.07.001.

43. Mykkänen O.T; Kalesnykas G,; Adriaens M,; Evelo C.T,; Törrönen R,; Kaarniranta K. Bilberries potentially alleviate stress-related retinal gene expression induced by a high-fat diet in mice. Mol Vis 2012, 18:2338-51. PMID: 22993483.

44. van Iersel M.P.; Kelder T.; Pico A.R.; Hanspers K.; Coort S.; Conklin B.R.; Evelo C. Presenting and exploring biological pathways with PathVisio. BMC Bioinformatics 2008, 25:9:399. DOI: 10.1186/1471-2105-9-399.

45. Iacobas, D.A.; Iacobas, S.; Tanowitz, H.B.; deCarvalho, A.C.; Spray, D.C. Functional genomic fabrics are remodeled in a mouse model of Chagasic cardiomyopathy and restored following cell therapy. Microbes Infect 2018, 20(3), 185-195. doi: 10.1016/j.micinf.2017.11.003.

46. Linden R; Perry V.H. Massive retinotectal projection in rats. Brain Res 1983, 272(1):145-9. DOI: 10.1016/0006-8993(83)90371-2.

47. Kravchick D.O.; Hrdinka M.; Iacobas S.; Iacobas D.A.; Kreutz M.R.; Jordan B.A. Synaptonuclear messenger PRR7 inhibits c-Jun ubiquitination and regulates NMDA mediated excitotoxicity. EMBOJ 2016, 35(17):1923-34.. doi: 10.15252/embj.201593070.

48. Lee, P.R.; Cohen, J.E.; Iacobas, D.A.; Iacobas, S.; Fields, R.D. Gene networks activated by pattern-specific generation of action potentials in dorsal root ganglia neurons. Sci Rep 2017, 7:43765, doi: 10.1038/srep43765.

49. Iacobas D.A.; Iacobas S.; Nebieridze N.; Velisek L.; Veliskova J. Estrogen protects neurotransmission transcriptome during status epilepticus. Front Neurosci 2018, 12:332. DOI: 10.3389/fnins.2018.00332.

50. Iacobas D.A.; Urban M.; Iacobas S.; Scemes E.; Spray D.C. Array analysis of gene expression in connexin 43 null astrocytes. Physiol Genomics 2003, 15(3):177-190. DOI: $\quad$ 10.1152/physiolgenomics.00062.2003.

51. Iacobas D.A.; Iacobas S.; Urban-Maldonado M.; Spray D. Sensitivity of the brain transcriptome to connexin ablation. Biochimica et Biofisica Acta 2005, 1711:183-196. DOI: 10.1016/j.bbamem.2004.12.002.

52. Iacobas D.A.; Chachua T.; Iacobas S.; Benson M.; Borges K.; Veliskova J.; Velisek L. ACTH and PMX53 recover synaptic transcriptome alterations in a rat model of infantile spasms. Sci Rep 2018, 8:5722. DOI:10.1038/s41598-018-24013-x.

53. Iacobas D.A.; Iacobas S.; Spray D.C. Connexin43 and the brain transcriptome of the newborn mice. Genomics 2007, 89(1):113-123. DOI:10.1016/j.ygeno.2006.09.007.

54. Iacobas S.; Ede N.; Iacobas D.A. The Gene Master Regulators (GMR) Approach Provides Legitimate Targets for Personalized, Time-Sensitive Cancer Gene Therapy. Genes 2019, 10(8): E560. doi:10.3390/genes10080560.

55. Szklarczyk D.; Morris J.H.; Cook H.; Kuhn M.; Wyder S.; Simonovic M.; Santos A.; Doncheva N.T.; Roth A.; Bork P.; Jensen L.J.; Mering C. The STRING database in 2017: quality-controlled protein-protein association networks, made broadly accessible. Nucleic Acids Res 2017, 45(Database issue):D362-D368. DOI: 10.1093/nar/gkw937.

56. Kutmon M.; van Iersel M. P.; Bohler A.; Kelder T.; Nunes N.; Pico A. R.; Evelo C.T. PathVisio 3: an extendable pathway analysis toolbox. PLoS Comput. Biol 2015, 11:e1004085. DOI: 10.1371/journal.pcbi.1004085.

57. Kanehisa M.; Goto S. KEGG: kyoto encyclopedia of genes and genomes. Nucleic Acids Res 2000, 28(1):27-30. DOI: 10.1093/nar/28.1.27.

58. Kuleshov M.V.; Jones M.R.; Rouillard A.D.; Fernandez N.F.; Duan Q.; Wang Z.; Koplev S.; Jenkins S.L.; Jagodnik K.M.; Lachmann A.; McDermott M.G.; Monteiro C.D.; Gundersen G.W.; Ma'ayan A. Enrichr: a comprehensive gene set enrichment analysis web server 2016 update. Nucleic Acids Res 2016, 44(W1):W90-7. DOI: 10.1093/nar/gkw377.

59. Sharma T.P.; Liu Y.; Wordinger R.J.; Pang I.H.; Clark A.F. Neuritin 1 promotes retinal ganglion cell survival and axonal regeneration following optic nerve crush. Cell Death Dis 2015, 6:e1661. DOI: 10.1038/cddis.2015.22. 
60. Spray D.C.; Iacobas D.A. Organizational principles of the connexin-related brain transcriptome. J Membr Biol 2007, 218(1-3):39-47. DOI:10.1007/s00232-007-9049-5.

61. Iacobas D.A.; Iacobas S.; Spray D.C. Connexin-dependent transcellular transcriptomic networks in mouse brain. Prog Biophys Mol Biol 2007, 94(1-2):168-184. DOI:10.1016/j.pbiomolbio.2007.03.015.

62. Adesse D.; Goldenberg R.C.; Fortes F.S.; Iacobas D.A.; Iacobas S.; Campos de Carvalho A.C.; de Narareth M.; Huang H.; Tanowitz H.B.; Garzoni L.R.; Spray D.C. Gap junctions and Chagas' disease. Adv Parasitol 2011, 76:63-81. doi: 10.1016/B978-0-12-385895-5.00003-7.

63. Piri N.; Kwong J.M.; Caprioli J. Crystallins in retinal ganglion cell survival and regeneration. Mol Neurobiol 2013, 48(3):819-28. DOI: 10.1007/s12035-013-8470-2.

64. Morozov V.; Wawrousek E.F. Caspase-dependent secondary lens fiber cell disintegration in $\alpha \mathrm{A}-/ \alpha \mathrm{B}$-crystallin double-knockout mice. Development 2006, 133:813-821. DOI: 10.1242/dev.02262.

65. Kamradt M.C.; Lu M.; Werner M.E.. The small heat shock protein alpha B-crystallin is a novel inhibitor of TRAIL-induced apoptosis that suppresses the activation of caspase-3. J Biol Chem 2005, 280:11059-11066. DOI: $10.1074 /$ jbc.M413382200.

66. Mao Y.W.; Liu J.P.; Xiang H.; Li D.W. Human alphaA- and alphaB-crystallins bind to Bax and Bcl-X(S) to sequester their translocation during staurosporine-induced apoptosis. Cell Death Differ 2004, 11:512-526. DOI: 10.1038/sj.cdd.4401384.

67. Munemasa Y.; Kwong J.M.; Caprioli J.; Piri N. The Role of $\alpha \mathrm{A}$ - and $\alpha \mathrm{B}$-Crystallins in the Survival of Retinal Ganglion Cells after Optic Nerve Axotomy. Invest Ophthalmol Vis Sci 2009, 50(8):3869-75. DOI: 10.1167/iovs.08-3138.

68. Macosko E.Z.; Basu A.; Satija R.; Nemesh J.; Shekhar K.; Goldman M.; Tirosh I.; Bialas A.R.; Kamitaki N.; Martersteck E.M.; Trombetta J.J.; Weitz D.A.; Sanes J.R.; Shalek A.K.; Regev A.; McCarroll S.A. Highly Parallel Genome-wide Expression Profiling of Individual Cells Using Nanoliter Droplets. Cell 2015, 161(5):1202-1214. DOI: 10.1016/j.cell.2015.05.002.

69. Nishikura K. A-to-I editing of coding and non-coding RNAs by ADARs. Nat Rev Mol Cell Biol 2016, 17:83-96. DOI: 10.1038/nrm.2015.4.

70. Dávalos V.; Súarez-López L.; Castaño J.; Messent A.; Abasolo I.; Fernandez Y.; Guerra-Moreno A.; Espín E.; Armengol M.; Musulen E.; Ariza A.; Sayós J, Arango D, Schwartz S Jr. Human SMC2 Protein, a Core Subunit of Human Condensin Complex, Is a Novel Transcriptional Target of the WNT Signaling Pathway and a New Therapeutic Target. J Biol Chem 2012, 287(52):43472-81. DOI: 10.1074/jbc.M112.428466.

71. Eyer J.; Peterson A. Neurofilament-deficient axons and perikaryal aggregates in viable transgenic mice expressing a neurofilament-B-galactosidase fusion protein. Neuron 1994,12:398-405. DOI: 10.1016/0896-6273(94)90280-1.

72. Ohara O.; Gahara Y.; Miyake T.; Teraoka H.; Kitamura T. Neurofilament deficiency in quail caused by nonsense mutation in neurofilament-L gene. J. Cell Biol 1993, 121:387-395. DOI: 10.1083/jcb.121.2.387.

73. Yum S. W.; Zhang J.; Mo K.; Li J.; Scherer S.S. A novel recessive Nefl mutation causes a severe, early-onset axonal neuropathy. Ann. Neurol 2009, 66:759-770. DOI: 10.1002/ana.21728.

74. Kittur S.; Hoh J.; Endo H.; Tourtellotte W.; Weeks B.S.; Markesbery W.; Adler W. Cytoskeletal neurofilament gene expression in brain tissue from Alzheimer's disease patients. I. Decrease in NF-L and NF-M message. J Geriatr Psychiatry Neurol 1994, 7(3):153-8. DOI: 10.1177/089198879400700305.

75. Torres V.I.; Vallejo D.; Inestrosa N.C. Emerging Synaptic Molecules as Candidates in the Etiology of Neurological Disorders. Neural Plast 2017, 2017:8081758. DOI: 10.1155/2017/8081758.

76. Nudo R.J. Recovery after brain injury: mechanisms and principles. Front Hum Neurosci 2013, 7:887. DOI: 10.3389/fnhum.2013.00887.

77. Risner M.L.; Pasini S.; Cooper M.L.; Lambert W.S. and Calkins DJ. Axogenic mechanism enhances retinal ganglion cell excitability during earlyprogression in glaucoma. Proc.Natl.Acad.Sci.USA 2018, 115(10):E2393-E2402. DOI: 10.1073/pnas.1714888115.

78. Weber A.J.; Harman C.D. Structure-function relations of parasol cells in the normal and glaucomatous primate retina. Invest Ophthalmol Vis Sci 2005, 46:3197-20. DOI: 10.1167/iovs.04-0834.

79. Yuan A.; Nixon R.A. Specialized roles of neurofilament proteins in synapses: Relevance to neuropsychiatric disorders. Brain Res Bull 2016, 126(Pt 3):334-346. DOI: 10.1016/j.brainresbull.2016.09.002.

80. Yuan A.; Sershen H.; Veeranna Basavarajappa B.S.; Kumar A.; Hashim A.; Berg M.; Lee J.H.; Sato Y.; Rao M.V.; Mohan P.S.; Dyakin V.; Julien J.P.; Lee V.M.; Nixon R.A. Neurofilament subunits are integral 
components of synapses and modulate neurotransmission and behavior in vivo. Mol Psychiatry 2015, 20(8):986-94. DOI: 10.1038/mp.2015.45.

81. Templeton J.P.; Freeman N.E.; Nickerson J.M.; Jablonski M.M.; Rex T.S.; Williams R.W.; Geisert E.E. Innate immune network in the retina activated by optic nerve crush. Invest Ophthalmol Vis Sci 2013, 9;54(4):2599-606. DOI: 10.1167/iovs.12-11175.

82. Panagis L.; Zhao X.; Ge Y.; Ren L.; Mittag T.W.; Danias J. Retinal gene expression changes related to IOP exposure and axonal loss in DBA/2J mice. Invest Ophthalmol Vis Sci 2011, 52:7807-7816. DOI: 10.1167/iovs.10-7063.

83. Steele M.R.; Inman D.M.; Calkins D.J.; Horner P.J.; Vetter M.L. Microarray analysis of retinal gene expression in the DBA/2J model of glaucoma. Invest Ophthalmol Vis Sci 2006, 47:977-985. DOI: 10.1167/iovs.05-0865.

84. Yasuda M.; Tanaka Y.; Ryu M.; Tsuda S.; Nakazawa T. RNA sequence reveals mouse retinal transcriptome changes early after axonal injury. PLoS One 2014, 9(3):e93258. DOI: 10.1371/journal.pone.0093258.

85. Berry R.H.; Qu J.; John S.W.M.; Howell G.R.; Jakobs T.C. Synapse Loss and Dendrite Remodeling in a Mouse Model of Glaucoma. PLoS One 2015, 10(12):e0144341. DOI: 10.1371/journal.pone.0144341.

86. Stephan A.H.; Barres B.A.; Stevens B. The complement system: an unexpected role in synaptic pruning during development and disease. Annu Rev Neurosci 2012, 35:369-89. DOI: 10.1146/annurev-neuro-061010-113810.

87. Stevens B.; Allen N.J.; Vazquez L.E.; Howell G.R.; Christopherson K.S.; Nouri N.; Micheva K.D.; Mehalow A.K.; Huberman A.D.; Stafford B.; Sher A.; Litke A.M.; Lambris J.D.; Smith S.J.; John S.W.; Barres B.A. The classical complement cascade mediates CNS synapse elimination. Cell 2007, 131(6):1164-78. DOI: 10.1016/j.cell.2007.10.036.

88. Schafer D.P.; Lehrman E.K.; Kautzman A.G.; Koyama R.; Mardinly A.R.; Yamasaki R.; Ransohoff R.M.; Greenberg M.E.; Barres B.A.; Stevens B. Microglia sculpt postnatal neural circuits in an activity and complement-dependent manner. Neuron 2012, 74(4):691-705. DOI: 10.1016/j.neuron.2012.03.026.

89. Pisalyaput K.; Tenner A.J. Complement component C1q inhibits beta-amyloid- and serum amyloid P-induced neurotoxicity via caspase- and calpain-independent mechanisms. J Neurochem 2008, 104(3):696-707. DOI: 10.1111/j.1471-4159.2007.05012.x.

90. Anderson S.R.; Zhang J.; Steele M.R.; Romero C.O.; Kautzman A.G.; Schafer D.P.; Vetter M.L. Complement Targets Newborn Retinal Ganglion Cells for Phagocytic Elimination by Microglia. J Neurosci 2019, 39(11):2025-2040. DOI: 10.1523/JNEUROSCI.1854-18.2018.

91. Medzhitov R. Origin and physiological roles of inflammation. Nature 2008, 454(7203):428-35. DOI: 10.1038/nature07201.

92. Shagdarsuren E.; Bidzhekov K.; Djalali-Talab Y.; Liehn E.A.; Hristov M.; Matthijsen R.A.; Buurman W.A.; Zernecke A.; Weber C. C1-esterase inhibitor protects against neointima formation after arterial injury in atherosclerosis-prone mice. Circulation 2008, 117(1):70-8. DOI: 10.1161/CIRCULATIONAHA.107.715649.

93. Nelson B.R.; Gumuscu B.; Hartman B.H.; Reh T.A. Notch activity is downregulated just prior to retinal ganglion cell differentiation. Dev Neurosci 2006, 28(1-2):128-41. DOI: 10.1159/000090759.

94. Hayes S.; Nelson B.R.; Buckingham B.; Reh T.A. Notch signaling regulates regeneration in the avian retina. Dev Biol 2007, 312(1):300-11. DOI: 10.1016/j.ydbio.2007.09.046.

95. Ghai K.; Zelinka C.; Fischer A.J. Notch Signaling Influences Neuroprotective and Proliferative Properties of Mature Müller Glia. J Neurosci 2010, 30(8):3101-12. DOI: 10.1523/JNEUROSCI.4919-09.2010.

96. Nagarsheth M.H.; Viehman A.; Lippa S.M.; Lippa C.F. Notch-1 immunoexpression is increased in Alzheimer's and Pick's disease. J. Neurol. Sci 2006, 244:111-116. DOI: 10.1016/j.jns.2006.01.007.

97. Lathia J.D.; Mattson M.P.; Cheng A. Notch: from neural development to neurological disorders. J. Neurochem 2008, 107:1471-1481. DOI: 10.1111/j.1471-4159.2008.05715.x.

98. Dutta D.; Mutsuddi M.; Mukherjee A. Synergistic interaction of Deltex and Hrp48 leads to JNK activation. Cell Biol Int 2019, 43(3):350-357. DOI: 10.1002/cbin.11089. 
Appendix 1

(a)

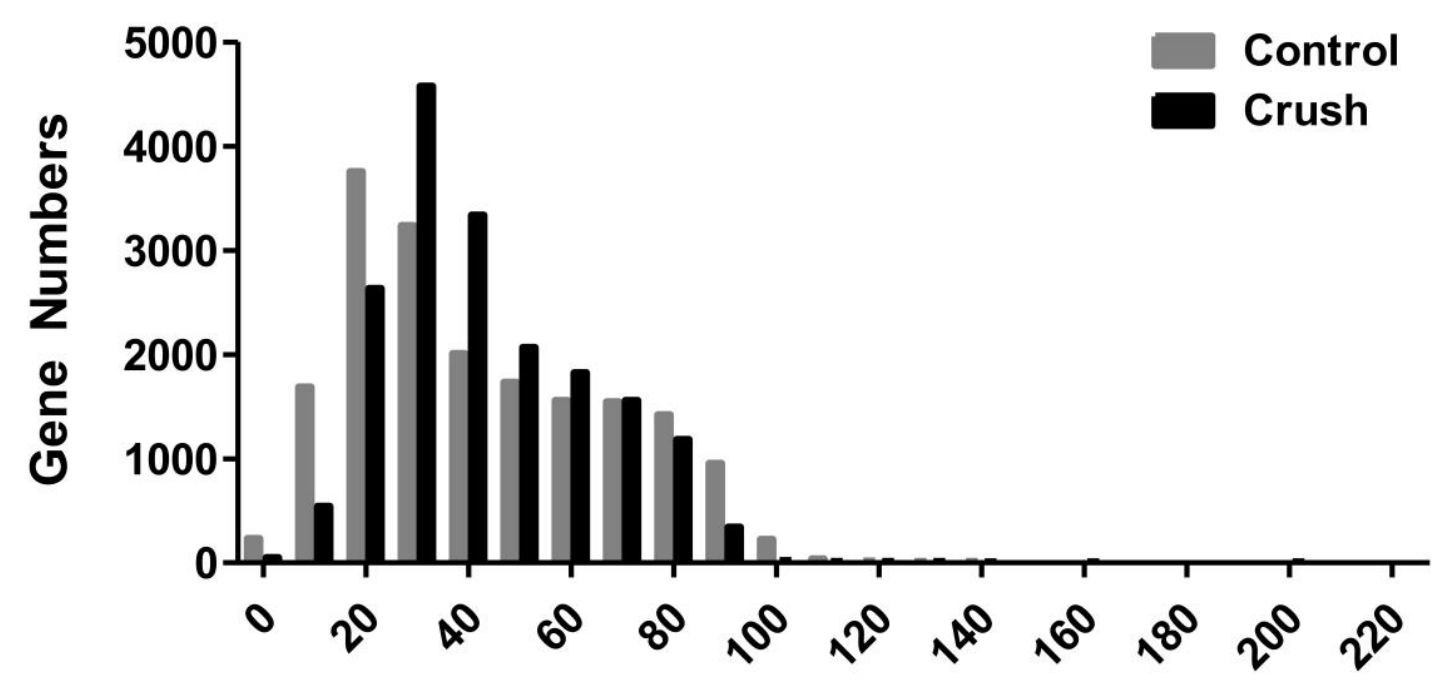

REV

(b)

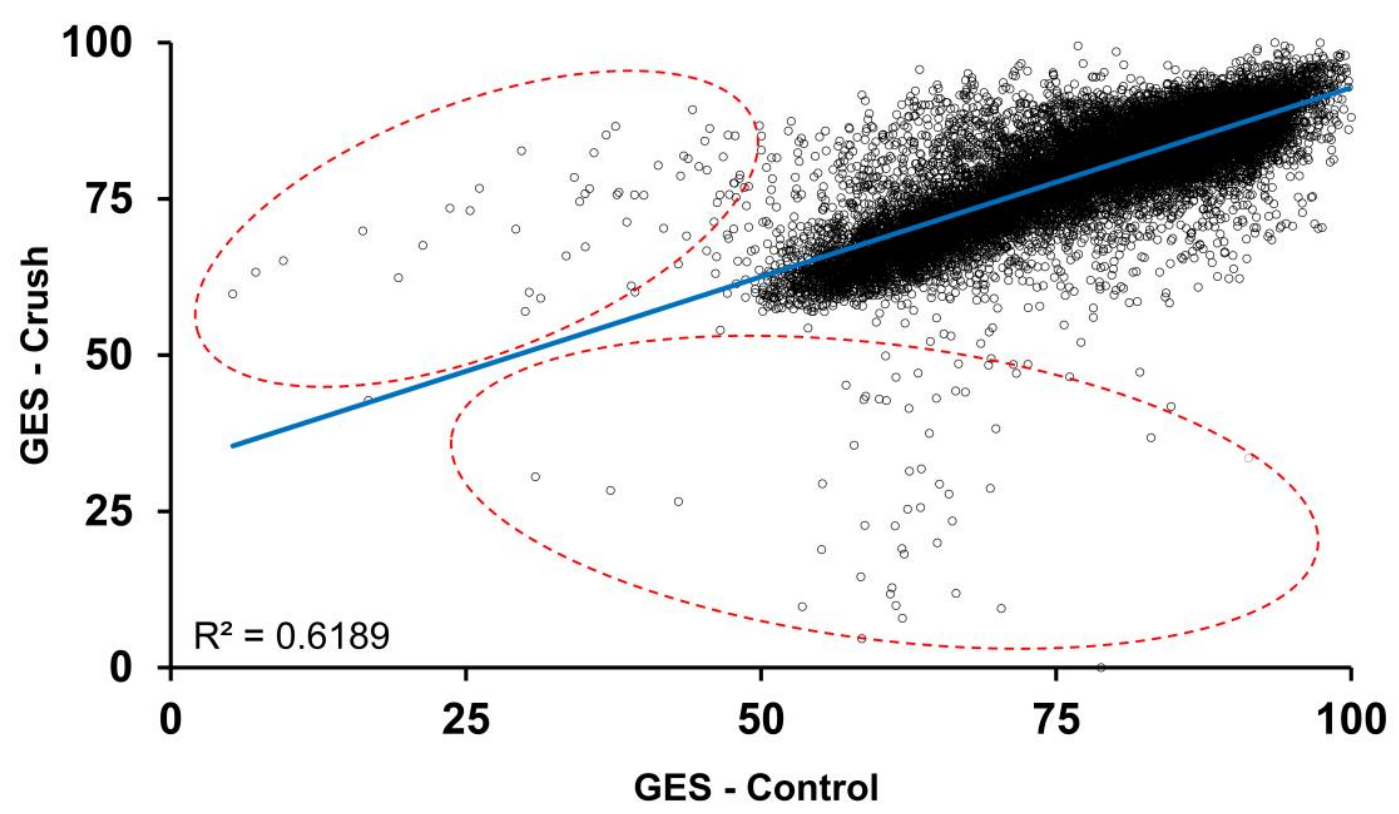

Figure S1: The relative estimated variability (REV) and gene expression stability (GES) of individual genes in each experimental condition. (a) Histogram of the REVs among the four replicas of Control and ONC experimental groups. REV profile of genes after ONC was very similar compared to that of control retinas, with a slight shift towards a higher variability. (b) Linear regression of the gene expression stability (GES) of individual genes in each experimental condition indicated a slight decrease of the very stably expressed genes (GES > 95) after ONC. Red circles contain genes that presented the highest change in their expression stability among experimental groups. 
Table S1: Top 50 Down-regulated genes in ONC vs CTR

\begin{tabular}{|c|c|c|c|}
\hline Gene name & Gene symbol & Fold change & $\rho$ value \\
\hline Neuritin 1 & Nrn1 & -18.82 & 0.0080 \\
\hline $\begin{array}{l}\text { Solute carrier family } 17 \text { (sodium-dependent inorganic } \\
\text { phosphate cotransporter) member } 6\end{array}$ & Slc17a6 & -14.95 & 0.0037 \\
\hline $\begin{array}{l}\text { Serine (or cysteine) peptidase inhibitor, clade B, } \\
\text { member } 1 \mathrm{~b}\end{array}$ & Serpinb1b & -12.79 & 0.0040 \\
\hline Peripherin & Prph & -12.69 & 0.00009 \\
\hline Neurofilament, medium polypeptide & Nefm & -11.77 & 0.0010 \\
\hline Neurofilament, heavy polypeptide & Nefh & -11.42 & 0.0079 \\
\hline Synuclein, gamma (breast cancer-specific protein 1) & Sncg & -10.76 & 0.0023 \\
\hline POU class 4 homeobox 2 & Pou $4 \mathrm{f} 2$ & -7.30 & 0.0088 \\
\hline Neurofilament, light polypeptide & Nefl & -6.79 & 0.0027 \\
\hline $\begin{array}{l}\text { Serine (or cysteine) proteinase inhibitor, clade B, } \\
\text { member 1a }\end{array}$ & Serpinb1a & -4.94 & 0.0028 \\
\hline $\begin{array}{l}\text { Tubulin polymerization-promoting protein family } \\
\text { member } 3\end{array}$ & Tppp3 & -4.56 & 0.0013 \\
\hline Transmembrane protein 163 & Tmem163 & -4.32 & 0.0010 \\
\hline Thy-1 cell surface antigen & Thy1 & -3.88 & 0.0272 \\
\hline Major facilitator superfamily domain containing 6 & Mfsd6 & -3.73 & 0.0008 \\
\hline Chemokine (C-X-C motif) ligand 13 & Cxcl13 & -3.05 & 0.0142 \\
\hline Sodium channel, voltage-gated, type IV, beta & Scn $4 b$ & -2.91 & 0.0050 \\
\hline ISL LIM homeobox 2 & Isl2 & -2.90 & 0.0067 \\
\hline Sodium channel, voltage-gated, type I, beta & Scn1b & -2.83 & 0.033 \\
\hline Calpain 1, (mu/I) large subunit & Capn1 & -2.79 & 0.0149 \\
\hline $\begin{array}{l}\text { RAS guanyl releasing protein } 2 \text { (calcium and } \\
\text { DAG-regulated) }\end{array}$ & Rasgrp2 & -2.69 & 0.0153 \\
\hline Sodium channel, voltage-gated, type II, alpha 1 & Scn2a1 & -2.59 & 0.0301 \\
\hline Regulator of G-protein signaling 4 & Rgs4 & -2.48 & 0.0052 \\
\hline Visinin-like 1 & Vsnl1 & -2.45 & 0.0212 \\
\hline Synaptotagmin II & Syt2 & -2.43 & 0.0250 \\
\hline NEL-like 2 (chicken) & Nell2 & -2.40 & 0.0006 \\
\hline L1 cell adhesion molecule & L1cam & -2.35 & 0.0466 \\
\hline Plastin 3 & Pls3 & -2.29 & 0.0141 \\
\hline F-box protein 2 & $\mathrm{Fbxo2}$ & -2.26 & 0.0041 \\
\hline Complexin 1 & Cplx1 & -2.25 & 0.0393 \\
\hline $\begin{array}{l}\text { ELAV (embryonic lethal, abnormal vision, Drosophila) } \\
\text {-like } 2 \text { (Hu antigen B) }\end{array}$ & Elavl2 & -2.21 & 0.0221 \\
\hline Microsomal glutathione S-transferase 3 & Mgst3 & -2.19 & 0.0044 \\
\hline N-acetyltransferase 8-like & Nat81 & -2.17 & 0.0155 \\
\hline
\end{tabular}




\section{Annexin A6}

Rho GTPase activating protein 32

Leucine-rich repeat LGI family, member 3

Tyrosine 3-monooxygenase/tryptophan

monooxygenase activation protein, eta polypeptide
Anxa6

Arhgap32

Lgi3

5- Ywhah

Ly6/neurotoxin 1

gb | Rattus

norvegicus

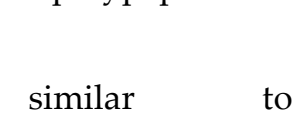

Lynx1

dehydrogenase
$-2.10$

$-2.08$

$-2.08$

$-2.05$

$-2.03$

0.0070

0.0275

glyceraldehyde-3-phosphate

(LOC304769), mRNA [XM_222600]
$-1.98$

0.0331 protein 3

FXYD domain-containing ion transport regulator 7

Sulfotransferase family $4 \mathrm{~A}$, member 1

Fxyd7

$-1.95$

0.0023

Tubulin, beta 3 class III

Sult4a1

Tubb3

Internexin neuronal intermediate filament protein, Ina alpha

Parvalbumin

Pvalb

Potassium voltage-gated

channel, Shal-related Kcnd2

subfamily, member 2

Heme binding protein 2

Hebp2

Panx2

Grem2

Gremlin 2

Ptgfrn

Tmod4

$-1.93$

0.0115

$-1.93$

0.0163

$-1.93$

0.0163

$-1.91$

0.0048

$-1.89$

0.0406

Prostaglandin F2 receptor negative regulator

Tropomodulin 4
$-1.89$

0.0306

$-1.89$

0.0050

$-1.86$

0.0147

$-1.82$

0.0021

$-1.81$ 
Table S2: Top 50 Up-regulated genes in ONC vs CTR

\begin{tabular}{|c|c|c|c|}
\hline Gene name & Gene symbol & Fold change & $\rho$ value \\
\hline $\begin{array}{l}\text { Cd74 molecule, major histocompatibility complex, } \\
\text { class II invariant chain }\end{array}$ & $\mathrm{Cd} 74$ & 25.60 & 0.0030 \\
\hline $\begin{array}{l}\text { tc|HG2A_RAT (P10247) H-2 class II histocompatibility } \\
\text { antigen gamma chain (MHC class II-associated } \\
\text { invariant chain) (Ia antigen -associated invariant chain) }\end{array}$ & TC588776 & 11.55 & 0.0100 \\
\hline (Ii) (CD74 antigen), partial (31\%) [TC588776] & & & \\
\hline follistatin-like 3 (secreted glycoprotein) & Fstl3 & 5.31 & 0.0176 \\
\hline Serpin peptidase inhibitor, clade $G$, member 1 & Serping1 & 3.49 & 0.0031 \\
\hline Eph receptor A2 & Epha2 & 3.31 & 0.0061 \\
\hline Ceruloplasmin (ferroxidase) & $\mathrm{Cp}$ & 3.29 & 0.0086 \\
\hline $\begin{array}{l}\text { ADAM metallopeptidase with thrombospondin type } 1 \\
\text { motif, } 1\end{array}$ & Adamts1 & 3.26 & 0.0097 \\
\hline Chitinase 3-like 1 (cartilage glycoprotein-39) & Chi311 & 2.89 & 0.0051 \\
\hline $\begin{array}{l}\text { Cysteine and glycine-rich protein } 3 \text { (cardiac LIM } \\
\text { protein) }\end{array}$ & Csrp3 & 2.69 & 0.0271 \\
\hline Leucine rich repeat containing 15 & Lrrc15 & 2.61 & 0.0036 \\
\hline Protein tyrosine phosphatase, receptor type, $\mathrm{O}$ & Ptpro & 2.58 & 0.0031 \\
\hline Keratin 19 & Krt19 & 2.57 & 0.0013 \\
\hline $\begin{array}{l}\text { Solute carrier family } 17 \text { (anion/sugar transporter), } \\
\text { member } 5\end{array}$ & Slc17a5 & 2.54 & 0.0175 \\
\hline Scavenger receptor class $\mathrm{A}$, member 3 & Scara3 & 2.47 & 0.0086 \\
\hline Ellis van Creveld syndrome 2 homolog (human) & Evc2 & 2.47 & 0.0449 \\
\hline Cysteine and glycine-rich protein 2 & Csrp2 & 2.44 & 0.0121 \\
\hline Complement component 1 , s subcomponent & $\mathrm{C} 1 \mathrm{~s}$ & 2.43 & 0.0157 \\
\hline S100 calcium binding protein A3 & S100a3 & 2.42 & 0.0366 \\
\hline Complement component 4A (Rodgers blood group) & $\mathrm{C} 4 \mathrm{a}$ & 2.41 & 0.0118 \\
\hline PR domain containing 9 & Prdm9 & 2.36 & 0.0225 \\
\hline Unknown & A_64_P105338 & 2.35 & 0.0068 \\
\hline Endothelin converting enzyme-like 1 & Ecel1 & 2.34 & 0.0199 \\
\hline TIMP metallopeptidase inhibitor 1 & Timp1 & 2.33 & 0.0115 \\
\hline Complement factor B & $\mathrm{Cfb}$ & 2.26 & 0.0046 \\
\hline Transmembrane protein 176A & Tmem176a & 2.19 & 0.0108 \\
\hline $\begin{array}{l}\text { Solute carrier family } 6 \text { (neurotransmitter transporter, } \\
\text { creatine), member } 8\end{array}$ & Slc6a8 & 2.18 & 0.0179 \\
\hline Janus kinase 3 & Jak3 & 2.17 & 0.0144 \\
\hline Complement component 3 & $\mathrm{C} 3$ & 2.17 & 0.0104 \\
\hline
\end{tabular}


Interferon regulatory factor 2 binding protein-like

$$
\text { Irf2bpl }
$$

0.0412

SMAD family member 1

Smad1

2.12

0.0045

Aminoadipate aminotransferase

Aadat

2.09

0.0316

Plexin D1

Plxnd1

2.09

0.0250

Transmembrane BAX inhibitor motif containing 1

Tmbim1

2.08

0.0143

S100 calcium-binding protein A4

S100a4

2.03

0.0038

EGF-containing fibulin-like extracellular matrix Efemp1

2.02

0.0229

protein 1

Interferon induced transmembrane protein 3

Ifitm3

2.00

0.0251

Interferon, alpha-inducible protein 27 like 2B

Ifi2712b

1.99

0.0214

Guanylate binding protein 2, interferon-inducible

Gbp2

1.96

0.0295

Ectonucleoside triphosphate diphosphohydrolase 2

Entpd2

1.96

0.0153

Interferon-induced protein 44-like

Ifi441

1.95

0.0349

Lipopolysaccharide-induced TNF factor

Litaf

1.94

0.0245

Connective tissue growth factor

Ctgf

1.94

0.0261

Notch1

Notch1

1.94

0.0087

Cytochrome b-245, alpha polypeptide

Cyba

1.93

0.0306

SP110 nuclear body protein

Sp110

1.93

0.0346

biogenesis of lysosomal organelles complex-1, subunit

Bloc1s3

1.91

0.0152

3

Tachykinin receptor 1

Tacr1

1.91

0.0335

Coiled-coil domain containing 87

Ccdc87

1.90

0.0331

Ataxin 7-like 2

Atxn712

1.90

0.0320

G protein-coupled receptor 37

Gpr37

1.87

0.0286 
Table S3. Cd74 and C3 increase expression in retinas ONC vs CTR

\begin{tabular}{ccccc}
\hline & & Microarray & \multicolumn{2}{c}{ qPCR } \\
\hline & ONC vs CTR & $\rho$-value & ONC vs CTR & $\rho$-value \\
Cd74 & 25.604 & 0.003 & 28.556 & 0.010 \\
C3 & 2.170 & 0.010 & 3.242 & 0.046 \\
\hline
\end{tabular}


Table S4. Disease signature of the down-regulated genes

\begin{tabular}{lll}
\hline Term & Overlap & $\rho$ value \\
\hline $\begin{array}{l}\text { Glaucoma associated with systemic syndromes DOID-1686 } \\
\text { mouse GSE26299 sample 491 }\end{array}$ & $38 / 341$ & $1.75 \mathrm{E}-50$ \\
$\begin{array}{l}\text { Glaucoma associated with systemic syndromes DOID-1686 } \\
\text { mouse GSE26299 sample 490 }\end{array}$ & & \\
$\begin{array}{l}\text { Glaucoma associated with systemic syndromes DOID-1686 } \\
\text { mouse GSE26299 sample 488 }\end{array}$ & $6.73 \mathrm{E}-27$ \\
$\begin{array}{l}\text { Spinal Cord Injury C0037929 rat GSE2599 sample 426 } \\
\text { Neurological pain disorder C0423704 rat GSE2636 sample }\end{array}$ & $5.36 \mathrm{E}-28$ \\
& $18 / 338$ & $5.15 \mathrm{E}-17$ \\
129 & & $5.95 \mathrm{E}-16$ \\
\hline
\end{tabular}


Table S5. Disease signature of the up-regulated genes

\begin{tabular}{|c|c|c|}
\hline Term & Overlap & $\rho$ value \\
\hline $\begin{array}{l}\text { Glaucoma associated with systemic syndromes DOID-1686 } \\
\text { mouse GSE26299 sample } 490\end{array}$ & $23 / 332$ & $1.28 \mathrm{E}-17$ \\
\hline Neurological pain disorder C0423704 rat GSE18803 sample 212 & $28 / 411$ & $3.79 \mathrm{E}-21$ \\
\hline $\begin{array}{l}\text { Glaucoma associated with systemic syndromes DOID-1686 } \\
\text { mouse GSE26299 sample } 489\end{array}$ & $21 / 350$ & 6.67E-15 \\
\hline Diabetic Retinopathy C0011884 rat GSE1979 sample 189 & $23 / 346$ & 3.19E-17 \\
\hline $\begin{array}{l}\text { Glaucoma associated with systemic syndromes DOID-1686 } \\
\text { mouse GSE26299 sample } 491\end{array}$ & $20 / 259$ & $2.48 \mathrm{E}-16$ \\
\hline
\end{tabular}


Table S6. Up-regulated pathways in ONC vs CTR retinas

\begin{tabular}{|c|c|c|c|c|c|c|}
\hline Pathway & positive (r) & measured (n) & total & $\%$ & Z Score & $\rho$-value (permuted) \\
\hline Complement Activation, Classical Pathway & 3 & 15 & 18 & $20.00 \%$ & 6.27 & 0 \\
\hline Complement and Coagulation Cascades & 5 & 56 & 63 & $8.93 \%$ & 4.96 & 0 \\
\hline Delta-Notch Signaling Pathway & 4 & 72 & 82 & $5.56 \%$ & 3.13 & 0.009 \\
\hline Oxidative Stress & 2 & 26 & 28 & $7.69 \%$ & 2.81 & 0.031 \\
\hline Notch Signaling Pathway & 2 & 32 & 45 & $6.25 \%$ & 2.41 & 0.017 \\
\hline Kit Receptor Signaling Pathway & 3 & 64 & 68 & $4.69 \%$ & 2.34 & 0.04 \\
\hline
\end{tabular}


Table S7. Previously described RGC markers downregulated in ONC vs CTR

\begin{tabular}{|c|c|c|c|}
\hline Gene name & Gene symbol & Fold change & $\rho$ value \\
\hline Neuritin 1 & Nrn1 & -18.82 & 0.0080 \\
\hline $\begin{array}{l}\text { Solute carrier family } 17 \text { (sodium-dependent inorganic } \\
\text { phosphate cotransporter) member } 6\end{array}$ & Slc17a6 & -14.95 & 0.0037 \\
\hline Peripherin & Prph & -12.07 & 0.00009 \\
\hline Neurofilament, medium polypeptide & Nefm & -11.77 & 0.001 \\
\hline Neurofilament, heavy polypeptide & Nefh & -11.42 & 0.0079 \\
\hline Synuclein, gamma (breast cancer-specific protein 1) & Sncg & -10.76 & 0.0023 \\
\hline POU class 4 homeobox 2 & Pou $4 \mathrm{f} 2$ & -7.30 & 0.0088 \\
\hline Neurofilament, light polypeptide & Nefl & -6.79 & 0.0027 \\
\hline $\begin{array}{l}\text { Tubulin polymerization-promoting protein family } \\
\text { member } 3\end{array}$ & Tppp3 & -4.56 & 0.0013 \\
\hline Thy- 1 cell surface antigen & Thy1 & -3.88 & 0.0272 \\
\hline Regulator of G-protein signaling 4 & Rgs4 & -2.48 & 0.005 \\
\hline Visinin-like 1 & Vsnl1 & -2.46 & 0.021 \\
\hline Synaptogmin 2 & Syt2 & -2.43 & 0.025 \\
\hline F-box protein 2 & $\mathrm{Fbxo} 2$ & -2.27 & 0.004 \\
\hline 3-monooxygenase/tryptophan & Ywhah & -2.05 & 0.0008 \\
\hline \multicolumn{4}{|l|}{ 5-monooxygenase activation protein, eta polypeptide } \\
\hline Tubulin, beta 3 class III & Tubb3 & -1.93 & 0.016 \\
\hline Pannexin 2 & Panx2 & -1.89 & 0.005 \\
\hline
\end{tabular}


Table S8. Enrichment analysis with genes had a dramatic change in their expression stability after ONC

\begin{tabular}{lll}
\hline Gene Ontology & Number of genes & Genes \\
\hline $\begin{array}{l}\text { Biological Process } \\
\text { Lens development in camera-type eye }\end{array}$ & 4 & Crygb, Crygc, Crygd and Crygs \\
Sensory organ development & 7 & Cryba4, Crybb2, Crygb, Crygc, Crygd, \\
Camera-type eye development & 6 & $\begin{array}{l}\text { Crygs and Krt13 } \\
\text { Colecular Function }\end{array}$ \\
$\begin{array}{ll}\text { Structural constituent of eye lens } \\
\text { Structural molecule activity }\end{array}$ & 9 & $\begin{array}{l}\text { and Crygs } \\
\end{array}$ \\
& 13 & $\begin{array}{l}\text { Cryaa, Cryba4, Crybb2, Crybb3, Crygb, } \\
\text { Crygc, Crygd, Crygs and Lim2 }\end{array}$ \\
\hline
\end{tabular}

